\title{
Numerical Simulations of Flow and Heat Transfer in a Wall-Bounded Pin Matrix
}

\section{S. Benhamadouche ${ }^{1} \cdot$ I. Afgan ${ }^{2}$ (D) $\cdot$ R. Manceau ${ }^{3,4}$}

Received: 30 March 2018 / Accepted: 11 June 2019 / Published online: 16 July 2019

(C) The Author(s) 2019

\begin{abstract}
A detailed computational study was performed for the case of a wall-bounded pin-fin-array in a staggered arrangement, representative of industrial configurations designed to enhance heat transfer. In order to evaluate the level of turbulence modelling necessary to accurately reproduce the flow physics at three (3) different Reynolds numbers $(3,000,10,000$ and $30,000)$, four models were selected: two eddy-viscosity URANS models $(k-\omega$-SST and $\phi$ model), an Elliptic Blending Reynolds-stress model (EB-RSM) and Large Eddy Simulation (LES). Global comparisons for the pressure loss coefficients and average Nusselt numbers were performed with available experimental data which are relevant for industrial applications. Further detailed comparisons of the velocity fields, turbulence quantities and local Nusselt numbers revealed that the correct prediction of the characteristics of the flow is closely related to the ability of the turbulence model to reproduce the large-scale unsteadiness in the wake of the pins, which is at the origin of the intense mixing of momentum and heat. Eddy-viscosity-based turbulence models have difficulties to develop such an unsteadiness, in particular around the first few rows of pins, which leads to a severe underestimation of the Nusselt number. In contrast, LES and EB-RSM are able to predict the unsteady motion of the flow and heat transfer in a satisfactory manner.
\end{abstract}

Keywords Large Eddy simulation · Nusselt number · Pressure distribution . Pin-fin-arrays · Unsteady Reynolds-averaged Navier-stokes

I. Afgan

imran.afgan@manchester.ac.uk

S. Benhamadouche

sofiane.benhamadouche@edf.fr

R. Manceau

remi.manceau@univ-pau.fr

EDF R\&D, Fluid Mechanics, Energy and Environment Department, 78401 Chatou, France

2 Modelling and Simulation Centre, School of MACE, The University of Manchester, Manchester, UK

3 CNRS / Univ Pau \& Pays Adour / E2S UPPA, Laboratoire de mathématiques et de leurs applications de Pau - Fédération IPRA, UMR5142, 64000 Pau, France

4 Inria Bordeaux-Sud-Ouest, Project-Team CAGIRE, Pau, France 


\section{Introduction}

Heat transfer augmentation has been an open question since the invention of the first Stirling engine in the early nineteenth century. Over the last 200 odd years various designs and techniques have been used to enhance the effective heat transfer between internal flow components such as heat transfer from a working fluid/solid to a passive fluid in solar thermal or nuclear applications. In thermal-hydraulics systems one of the main objectives is thus the effective heat transfer with minimum pressure drop across the working system. The current test-case consists of the flow through a wallbounded pin matrix in a staggered arrangement with a heated bottom wall. In addition to the complex underlying flow physics, this case is close to several industrial configurations found in internal cooling of gas-turbine blades, electronic devices and nuclear thermal-hydraulics. The use of pin-fin-arrays has proved to be an effective technique in achieving enhanced rates of heat transfer in the past. Some of the earlier experimental studies done by [1-4] and more recently by [5-9] report a number of flow characteristics including the heat transfer and pressure loss coefficients through various configurations of pin-fin-arrays.

Of particular interest among these are the experiments of [5-8] which were chosen as test case for the $15^{\text {th }}$ ERCOFTAC-SIG15/IAHR Workshop on Refined Turbulence Modelling held at Chatou in 2011. This particular test case was chosen for the workshop to assess and examine the suitability of various advanced modelling techniques/methods for flow and heat transfer calculations in complex, practice-relevant situations. The present work reported in this paper made a major contribution to this workshop [10] and the full set of current results can be accessed through the ERCOFTAC Knowledge Base Wiki; ${ }^{1}$ later referred to as ERCOFTAC-KB-Wiki for simplicity. Various numerical studies conducted prior to the workshop, such as the Unsteady Reynolds-Averaged Navier-Stokes (URANS) calculations by [11, 12], and hybrid Reynolds-Averaged Navier Stokes/Large Eddy Simulation by [13] also formed the baseline for numerical contributions along with the experimental data of [5-8] for the workshop.

The aim of the present study is to evaluate different strategies for modelling turbulence in the pin-fin-array test case of the workshop. Of particular importance is the determination of the level of modelling necessary to predict the main characteristics of the flow and heat transfer. In the past, URANS has been shown to be able to reproduce $2 \mathrm{D}$ and $3 \mathrm{D}$ wakes of bluff bodies [14, 15], but heat transfer predictions in complex flows close to industrial configurations, such as the wall-bounded pin matrix, are still very challenging. LES is undoubtedly a good candidate for reproducing the physics of such flows accurately, but at a cost unaffordable for high Reynolds numbers, such that comparing LES with lower-cost URANS methods, is of great interest to industry.

The present paper starts with the description of the experimental and numerical test cases (Section 2), followed by discussion of numerical treatment given in Section 3. This will be followed by discussions of some of the main results in Sections 4 and 5; the full set of results can be found in the ERCOFTAC Knowledge Base Wiki. ${ }^{1}$

\footnotetext{
${ }^{1}$ http://www.kbwiki.ercoftac.org/w/index.php/Abstr:UFR_4-18
} 


\section{Test Case Description}

\subsection{Experimental setup}

The experiments of [5-7] and [8] were conducted in a small bench top wind tunnel for a staggered pin-fin-array consisting of 8 rows with $7 \frac{1}{2}$ pins per row (see Fig. 1). Both the cross passage $(S / D)$ and stream-wise $(X / D)$ pin spacing ratios were equal to 2.5 while the pin height to diameter $(H / D)$ ratio was equal to 2 . The pin diameter $(D)$ was chosen to be equal to $2.54 \mathrm{~cm}$. The test section began at $7.75 \mathrm{D}$ upstream of the centerline of the first row of pins and ended 7.75D downstream of the centerline of the last row. The inlet total temperature and static pressure were measured on the centerline, $5 D$ upstream of row 1 , whereas the exit static pressure was measured $5 D$ downstream of row 8 . Tests were conducted at three Reynolds numbers: 3,000, 10,000, and 30,000 which were based on the maximum gap velocity $\left(V_{G}\right)$ and the pin diameter $(D)$. The gap bulk velocity was determined between two adjacent pins of the same row. The readers are referred to the ERCOFTAC-KB-Wiki for further details about the experimental setup, results and data uncertainties. The remaining description will focus on the numerical test-case which is studied and on the data utilized for the present comparisons.

\subsection{Computational setup}

The computational domain shown in Fig. 2a, consisting of 8 by 2 pins, was used for all the simulations. The chosen domain is essentially a sub-domain of the experimental setup with the assumption of lateral $(Y-$ axis) periodicity. All solid surfaces (pins, bottom and top walls) were set as no-slip solid walls. The inlet of the channel was set at a distance $L_{U}=10 D$ upstream of the center of the first row of pins, whereas the outlet was $L_{D}=$ $15 D$ downstream of the center of the last row of pins (this gives $X_{\text {inlet }}=-10 D$ and $\left.X_{\text {outlet }}=32.5 \mathrm{D}\right)$, respectively. Note that these two distances were both equal to $7.75 \mathrm{D}$ in the experimental setup but are not sufficient to perform reliable CFD calculations (see [16] and [17]), in particular the upstream distance, unless one represents the nozzle of the experiment which would lead to added computational costs. On the other hand, the height of the computational model was set to match the experimental set-up, $H=2 D$.

For the computations, the temperature was treated as a passive scalar with an imposed temperature at the inlet, and an imposed heat flux at the bottom wall with adiabatic conditions elsewhere. For the Large Eddy Simulations (LES), a uniform inflow velocity was
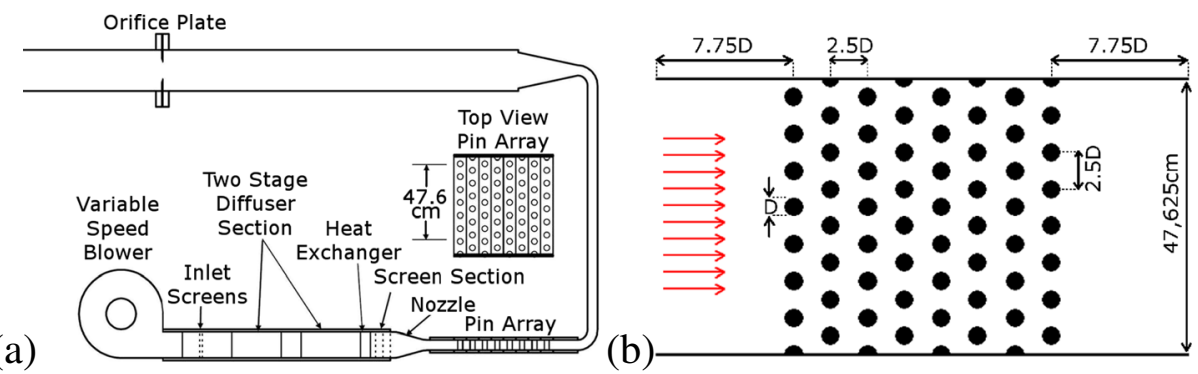

Fig. $12 \mathrm{D}$ sketch of [8] experiment. (a) Complete experimental setup (b) Top view of the pin-fin configuration 
(a)

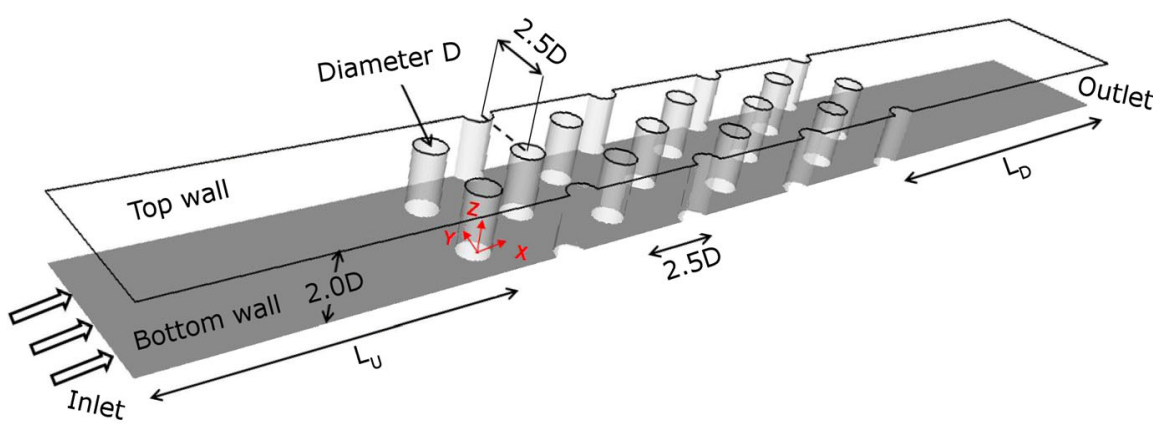

(b)

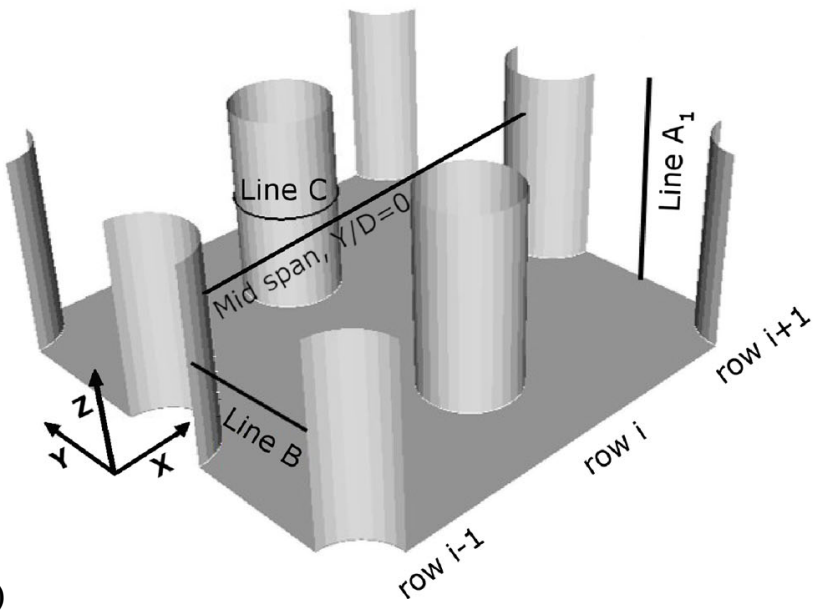

Fig. 2 (a) Sketch of the complete computational domain (b) Row numbering and lines (A1, B and C) locations. $i=1, . ., 8$. Line A1: $(X=2.5 D(i-1), Y=0$ if $i$ is even and $Y=1.25 D$ if $i$ is odd, $0 \leq Z \leq 2 D)$. Line B: $(X=2.5 D(i-1),-0.75 D \leq Y \leq 0.75 D$ if $i$ is even and $0.5 D \leq Y \leq 2 D$ if $i$ is odd, $Z=D)$. Line $\mathrm{C}$ : Centerline of the cylinder $(\bar{Z}=\bar{D}), 0^{0}$ at the leading edge (sense of rotation: counter clockwise with $Z$-axis from bottom to top wall)

imposed without any synthetic or precursor turbulence generation. Note that the reported inflow turbulence intensity in the experiment was about $1.4 \%$. In fact, different inlet conditions would have certainly affected the flow around the first and the second rows but not around the subsequent rows. On the other hand, for URANS a uniform velocity and 5\% turbulence intensity were imposed at the inlet. This latter condition triggers the production of the Reynolds stresses, mandatory for their development. Some tests (not reported herein) which were carried out without inlet turbulence showed that the computations degenerate to a solution where the Reynolds stresses vanish. However, preliminary tests also showed that the level of inlet turbulence intensity only affects the flow around the first two rows and that a value of 5\% leads to results in better agreement with the measurements. The inlet condition for the dissipation rate $(\varepsilon)$ in URANS was given by the standard relation used for internal flows

$$
\varepsilon=\frac{C_{\mu}^{3 / 4} k^{3 / 2}}{0.1 \kappa H}
$$

where $k$ is the turbulent kinetic energy, $H=2 D$ (the height of the channel), $\kappa=0.42$ and $C_{\mu}=0.09$. Isotropy of turbulence is assumed at the inlet for the Reynolds-stress model. 
For the computations, a Cartesian co-ordinate system was used with $X, Y$ and $Z$-axes in the stream-wise, span-wise (lateral) and wall-normal directions, respectively. 1-D profiles were drawn along lines A1, B \& C (see Fig. 2b) for post-processing/comparisons. The main lines for the velocity components and the Reynolds stresses were A1 and B and the main line for the pressure coefficient was $\mathrm{C}$ (mid-span location). The exact positions of the lines were:

- A1 - Line at mid-span $(Y / D=0)$ location between two adjacent pins of the same row along the channel height ( $Z$-axis).

- B - Surface to surface line between two adjacent pins of the same row at mid channel height $(Z / D=1.0)$ along the lateral $(Y)$ direction.

- C - Circumferential line around the pin surface from $0^{0}-180^{\circ}$, at mid channel height $(Z / D=1.0)$. Angle zero $\left(0^{0}\right)$ on the leading edge of the pins with a counter-clockwise orientation.

The local Nusselt number is given by $N u=q_{w} D /\left(\lambda\left(T_{w}-T_{r e f}\right)\right)$ where $\lambda$ is the thermal conductivity, and $T_{w} \& T_{\text {ref }}$ are the time averaged temperatures at the wall and the reference value, respectively. $T_{\text {ref }}$ takes into account the increase in the bulk temperature of the fluid from the heated surface as it flows down the array (see [18]). Therefore, at a given $X$ location, one gets: $T_{r e f}=q_{w} S_{h}(X) /\left(\rho C_{p} V_{0} S_{i}\right)$, where $S_{h}(X)$ is the heated surface from the inlet to $X$. [18] used an estimate of this surface $S_{h}=\left(-X_{\text {inlet }}+X\right) S_{\text {htot }} / L_{X}$ where $X_{\text {inlet }}$ is the $X$ coordinate of the inlet plane, $S_{\text {htot }}$ the total heated surface (here the surface is from $X_{\text {inlet }}$ to $\left.X_{\text {outlet }}\right)$ and $L_{X}$ the total length of the domain $\left(L_{X}=X_{\text {outlet }}-X_{\text {inlet }}\right) . \rho$, $C_{p}$ and $S_{i}$ are the fluid density, the specific heat and the inlet surface area, respectively.

\section{Numerical Treatment and Models}

\subsection{General description of the computations}

All numerical simulations were performed using the Électricité de France (eDF) in-house open source solver Code_Saturne (http://code-saturne.org) [19]. The code is based on an unstructured collocated finite-volume approach for cells of any shape. It uses a predictor/corrector method with Rhie and Chow interpolation [20] and a SIMPLEC algorithm, [21] for the pressure correction. For LES, pure second-order central differencing scheme was applied for the velocity components whereas for the temperature a central difference scheme with a slope test was used. Here the slope test determines whether to use a pure central scheme or to use first-order upwinding based on limiting of the overshoots. It is worth mentioning here that the slope test is done locally both in time and space. The time-advancing scheme was second-order, based on Crank-Nicolson/Adams Bashforth (the scheme for diffusion including the velocity gradient was totally implicit, for convection semi-implicit and for diffusion including the transpose of the velocity gradient explicit). For URANS, a centered scheme with a slope test was used for the velocity components and the temperature, whereas a first-order upwind scheme was utilized for the turbulence quantities. The time-advancing scheme in this case was first-order Euler which needs substantially smaller time steps for stability reasons. However, the use of the first-order Euler scheme here is justified as it is substantially faster than a second-order semi-implicit scheme such as the one used for the LES simulations.

Three Reynolds numbers were computed: $R e_{D}=3,000$ only with LES, $R e_{D}=10,000$ with both LES and URANS and $R e_{D}=30,000$ only with URANS. For the test cases the 
experimental flow conditions are listed in Table 1. For the computations a Prandtl number of 0.71 was used with fluid thermal conductivity defined as $\lambda=1 /\left(\operatorname{Pr} \operatorname{Re} e_{D}\right)$. The temperature was treated as a passive scalar with the inlet temperature set as $0^{0}$ and the imposed heat flux set to unity. Zero-gradient boundary conditions were used for all the variables at the outlet and an implicit periodic condition was set in the lateral direction for all the variables. All the computations were run on EDF BlueGene/P and BlueGene/Q supercomputers using up to 4096 cores costing just under 3 million core Central Processing Unit (CPU) hours (approximately 45,000 kAU) for each LES simulation and around 2 million (approximately $30,000 \mathrm{kAU}$ ) for each URANS simulation.

\subsection{Turbulence models}

The LES implementation in Code_Saturne [22] is based on the dynamic Smagorinsky model [23] with Lilly's minimization [24] in which the Smagorinsky constant $C_{S}$ is clipped below zero and above 0.065 . This model has been successfully used for flows around bluff bodies and in turbo-machinery; please see the effect of clipping of $C_{S}$ in [25]. A turbulent Prandtl number of 0.5 was used when solving for the temperature with LES, see [26].

In the current study three low Reynolds number URANS models were chosen based on their availability and relative popularity in the heat transfer community: the $k-\omega$-SST model [27], the $\phi$-model [28] and the EB-RSM model [29].

The $k-\omega$-SST model uses a blending between the standard $k-\omega$ and $k-\varepsilon$ models. The $\phi$ model uses the elliptic relaxation concept introduced by [30]. It is a stabilized version of the $\overline{v^{2}}-f$ model [14], based on the variable $\phi=\overline{v^{2}} / k$, where $\overline{v^{2}}$ characterizes the energy of the wall-normal fluctuations and is used in the evaluation of the eddy viscosity. For the present study, in both eddy-viscosity models, a Simple Gradient Diffusion Hypothesis (SGDH) was used for the temperature equation with a turbulent Prandtl number of 0.9.

The EB-RSM model proposed by [31] and later modified by [29] is inspired by the elliptic relaxation concept for the Reynolds stresses. Instead of using six relaxation equations, it solves one elliptic equation for a parameter $\alpha$ which is equal to zero at the wall and goes to 1 far from the wall. This parameter is then used to blend near-wall and remote (away from the wall) regions for the redistribution and dissipation terms of the Reynolds-stress transport equations. In the current formulation the EB-RSM uses the Speziale, Sarkar and Gatski model [32] for the homogeneous part of the redistribution term. For the temperature equation a Generalized Gradient Diffusion Hypothesis (GGDH) approach is used with a constant of 0.23 . In the present simulations the use of more advanced models such as the AFM (Algebraic Flux Model), the EB-AFM or the EB-GGDH [33] did not affect the results for global quantities such as the mean Nusselt number. This suggests that in the forced

Table 1 Experimental flow conditions

\begin{tabular}{lllllll}
\hline$R e_{D}$ & $T_{\text {inlet }}(K)$ & $V_{0}(\mathrm{~m} / \mathrm{s})$ & $v\left(\mathrm{~m}^{2} / \mathrm{s}\right)$ & $C(\mathrm{~J} / \mathrm{kg} / K)$ & $\lambda(\mathrm{W} / \mathrm{m} / K)$ & $q\left(W / \mathrm{m}^{2}\right)$ \\
\hline 3,000 & 300 & 1.06 & 0.000015 & 1005 & 0.0255 & 100 \\
10,000 & 300 & 3.54 & 0.000015 & 1005 & 0.0255 & 300 \\
30,000 & 300 & 10.62 & 0.000015 & 1005 & 0.0255 & 1000
\end{tabular}

Reynolds number based on pin diameter $\left(R e_{D}\right)$, inlet temperature $\left(T_{\text {inlet }}\right)$, inflow velocity $\left(V_{0}\right)$, fluid viscosity $(v)$, specific heat at constant pressure $(C)$, thermal conductivity $(\lambda)$, prescribed wall heat flux $(q)$ 


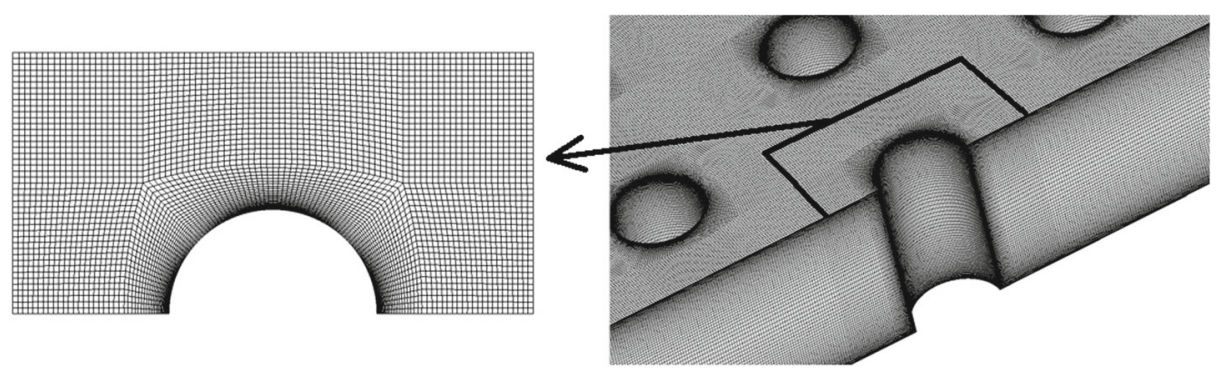

Fig. 3 Computational mesh used for LES at $R e_{D}=3,000$

convection regime, good predictions of heat transfer can be obtained with simple models for temperature diffusion as long as the dynamics of the flow is accurately resolved.

\subsection{Computational meshes}

Figure 3 shows the zoomed in views of the mesh used for LES at $R e_{D}=3,000$. The mesh resolutions for the different computations are given in Table 2 (see table caption for details).

Note that for URANS, only the parameters used for the finest grid are mentioned. The two coarser levels were obtained by coarsening the grid spacing by a factor of 2 in all the directions. Particular attention was paid to the grid refinement near the solid walls. Two meshes containing 18 million and 76 million cells were utilized in LES to simulate the two Reynolds numbers $R e_{D}=3,000$ and $R e_{D}=10,000$, respectively, ensuring that the non-dimensional wall distance of the first computational cell $\left(n^{+}\right)$remained below 2 almost everywhere. Moreover, it was also carefully checked that the near-wall cells satisfy the usual refinement criteria. The current non-dimensional values of $y^{+} \approx 2$ and $\Delta z^{+} \leq 40$, clearly satisfy the resolved LES refinement criteria of $y^{+}<2, \Delta x^{+}=50-150$ and $\Delta z^{+}=15-40,[34,35]$ (also see the wall treatment figures in the ERCOFTAC-KB-Wiki for further details).

An additional way to ensure that the mesh is sufficiently fine is to carry out simulations without using a subgrid-scale ( $s g s$ ) model in order to quantify its effect on the solution. It was observed that the influence of the sgs model was very limited for the present level of mesh refinement (see the Sensitivity to the sub-grid scale model section and relevant figures in the ERCOFTAC-KB-Wiki for details).

Table 2 Mesh information

\begin{tabular}{lllllll}
\hline Computation & $n b$ & $n b_{\theta}$ & $n b_{z}$ & $n_{\theta} / D$ & $n_{z} / D$ & $n_{z h} / D$ \\
\hline LES $\operatorname{Re}_{D}=3,000$ & 18.2 million & 176 & 90 & 0.0028 & 0.0065 & 0.0536 \\
LES $R e_{D}=10,000$ & 76.2 million & 320 & 120 & 0.0015 & 0.0019 & 0.0584 \\
URANS(*) $R e_{D}=10,000$ & 17 million & 128 & 112 & 0.00075 & 0.001 & 0.065 \\
URANS(*) $R e_{D}=30,000$ & 29 million & 128 & 160 & 0.00025 & 0.00025 & 0.0625 \\
\hline
\end{tabular}

(*) Only the information of the finest meshes is given. Total number of cells in the domain $(n b)$, number of cells around the pins in circumferential direction $\left(n b_{\theta}\right)$, number of cells in the wall normal $(Z)$ direction $\left(n b_{z}\right)$, normalized wall-adjacent cell size in the wall normal direction around the pins $\left(n_{\theta} / D\right)$, normalized wall-adjacent cell size in the wall normal direction-at the bottom wall $\left(n_{z} / D\right)$, -at the top wall $\left(n_{z h} / D\right)$ 


\subsection{Grid Convergence study for URANS}

A separate grid convergence study was performed for all the three URANS models at the two higher Reynolds numbers. Here only the study performed for $\operatorname{Re}_{D}=10,000$ with the EB-RSM model is presented for the grid convergence study as conclusions for all other models were similar. Three levels of refinement were used for all the models as described before.

Figure $4 \mathrm{a}$ and $\mathrm{b}$ show the mean stream-wise velocity and the pressure coefficient along the line B (pin mid-line) for the $R e_{D}=10,000$ case for row 3 , respectively. As the computations were unsteady, the r.m.s. values, or more generally the Reynolds stresses were combined as the sum of the resolved and modelled parts: $R_{i j}=R_{i j}^{r e s}+R_{i j}^{\text {mod }}$. These modelled and resolved parts are not shown in the current paper but can be downloaded from the ERCOFTAC-KB-Wiki database. It is observed from Fig. 4 that the coarse mesh results are very far from the experiments. However, the two finest meshes only show slight difference in profiles. Thus, the discussions in Sections 4 and 5 are based on the results obtained with the finest mesh (called here "very fine mesh"). In order to gain confidence in the finest mesh results, a further sensitivity study on the numerical discretization schemes with and without slope test was also performed. Based on the results it was concluded that the use of a centered scheme for the turbulent quantities did not affect the results. Other tests were also carried out such as introducing outer iterations for pressure/velocity coupling but none of them exhibited a noticeable effect on the results and are hence not reported here (please see the Sensitivity study to convection scheme on the ERCOFTAC-KB-Wiki database for detailed plots).

Table 3 summarizes the main computations for which results are reported in Sections 4 and 5. Note that all simulations were run for a substantially long period of time for the flow to fully develop. For the simulations a complete flow through pass was defined based on the time the flow took from the inlet of the domain to the outlet, $T_{\text {Pass }}$. Based on this, the total number of passes over which each of the individual cases were run ( ot $_{\text {Pass }}=$ Total Simulation time $\left./ T_{\text {Pass }}\right)$ and the number of passes over which the flow statistics were averaged (Ave Pass), are given in Table 3. The maximum local CFL number for each of the cases is also given in the same table which is less than 1 for all LES simulations and less than 2 for URANS.
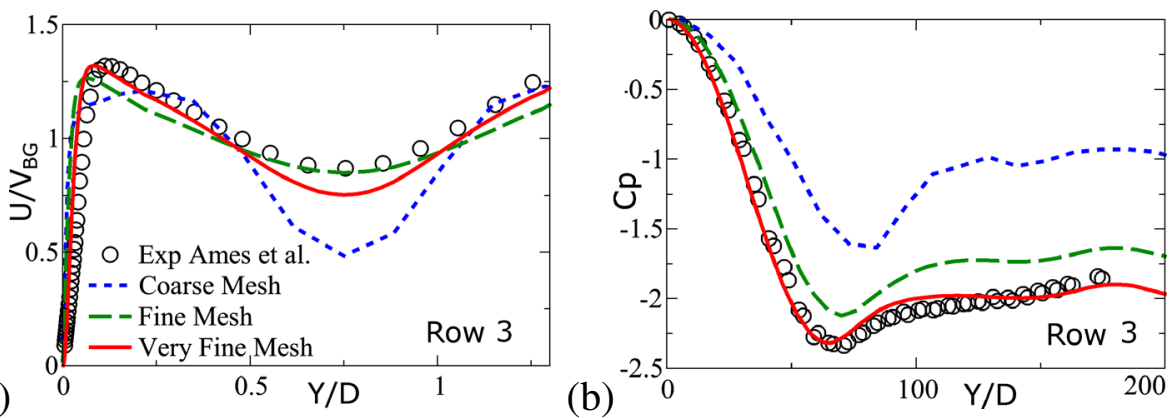

Fig. 4 Grid convergence study: (a) Mean stream-wise velocity (b) mean pressure coefficient profiles along the pin mid-line (Line-B) obtained using EB-RSM at $R e_{D}=10,000$ 
Table 3 Parameters of the main computations which are reported in the current paper

\begin{tabular}{llllllll}
\hline Test-case & $\operatorname{Re}_{D}$ & $V_{B G}$ & $V_{0}$ & Timestep $^{+}$ & Tot $_{\text {Pass }}$ & Ave Pass & $\overline{C F L}_{\text {max }}$ \\
\hline LES DynSmag & 3,000 & 2.02 & 1.21 & 0.0015 & 39 & 16 & 0.8 \\
LES DynSmag & 10,000 & 6.18 & 3.71 & 0.0002 & 11 & 7 & 0.8 \\
EB-RSM & 10,000 & 6.18 & 3.71 & 0.001 & 43 & 20 & 1.8 \\
$\phi-$ model & 10,000 & 6.18 & 3.71 & 0.001 & 44 & 36 & 1 \\
$k-\omega$-SST & 10,000 & 6.18 & 3.71 & 0.001 & 43 & 32 & 1.3 \\
EB-RSM & 30,000 & 18.53 & 11.12 & 0.0000625 & 11 & 9 & 0.6 \\
$\phi-$ model & 30,000 & 18.53 & 11.12 & 0.00025 & 19 & 14 & 0.9 \\
$k-\omega$-SST & 30,000 & 18.53 & 11.12 & 0.00025 & 22 & 16 & 1.8
\end{tabular}

Where Timestep ${ }^{+}$is the non-dimensional time step, Tot Pass the number of total flow through passes and Ave $_{\text {Pass }}$ is the number of passes over which the flow statistics were averaged

\section{Results and Discussions (Global Quantities)}

\subsection{Pressure loss coefficient}

In this section we discuss the measured values of the pressure loss coefficient in Ames et al. experiments as well as those obtained from the current numerical simulations at the three computed Reynolds numbers. The pressure loss coefficient is based on the total pressure drop from the inlet to the outlet of the domain and is defined as $f=\Delta P /\left(2 \rho V_{B G}^{2} N\right)$, where $N$ is the number of rows.

Figure 5a shows the computed pressure loss coefficient comparison with the measured values of Ames et al. and correlations of [36] and [2]

Jacob [36]:

$$
f=\left(0.25+0.1175 /(P / D-1)^{1.08}\right) R e^{-0.16}
$$

Metzger et al. [2]:

$$
\begin{gathered}
f=0.317 \operatorname{Re}_{D}{ }^{-0.132} \text { for } \operatorname{Re}_{D}<10^{4} \\
f=1.76 \operatorname{Re}_{D}{ }^{-0.318} \text { for } \operatorname{Re}_{D}>10^{4}
\end{gathered}
$$

Table 4 compares various computations to the experiments and gives the relative errors. LES shows a very good agreement with the [2] correlation and Ames et al. experimental results. The relative error is equal to $1 \%$ and $3 \%$ for the two computed Reynolds numbers, respectively. The EB-RSM model shows a satisfactory pressure loss coefficient at $R e_{D}=$ 10,000 ( $1 \%$ error) but the result is worse at $R e_{D}=30,000$ (where the error is $10 \%$ ). The $k-\omega$-SST model also exhibits globally good results (7\% and $6 \%$ errors). On the other hand the $\phi$-model gives the worst results with errors of $17 \%$ and $12 \%$ for the two Reynolds numbers, respectively. This will be further explained in Section 5.2 later. Wall resolved LES can thus be seen as an excellent candidate to obtain satisfactory pressure loss coefficients in the present configuration. It is important to note here that although the $k$ - $\omega$-SST model exhibits good results for the pressure loss coefficient, the physics of the present flow is not properly captured as will be shown later and thus one cannot rely on this model. 
(a)

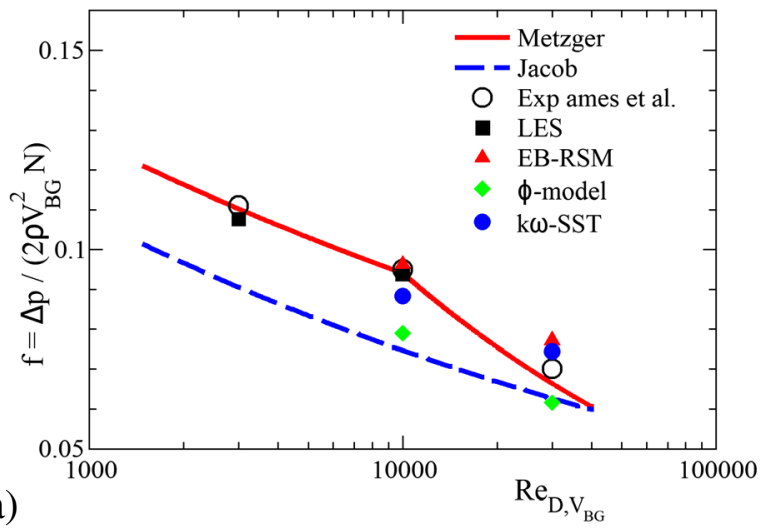

(b)

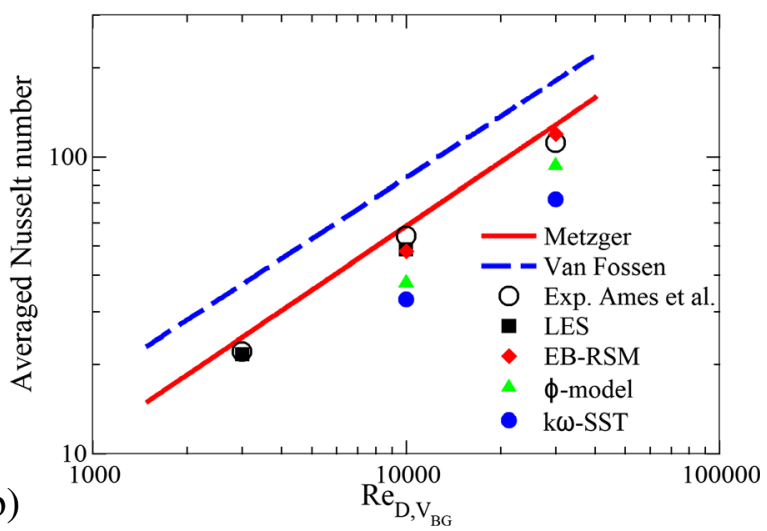

Fig. 5 (a) Pressure loss coefficient (b) Average Nusselt number at the bottom wall

\subsection{Average Nusselt number comparisons}

Figure $5 \mathrm{~b}$ shows all comparisons between simulations, experiments provided by Ames et al. and the correlations of [4] and [2].

Table 4 Pressure loss coefficient for the different computations compared to Ames et al. experimental values

\begin{tabular}{llllll}
\hline$R e_{D}=3,000$ & Exp.. & $L E S$ & & & \\
Value & 0.111 & 0.1076 & & & \\
Error $(\%)$ & - & 3 & & & $k-\omega$-SST \\
$R e_{D}=10,000$ & Exp. & $L E S$ & $0 B-R S$ & $\phi$ & 0.0883 \\
Value & 0.095 & 0.0939 & 0.0963 & 0.0789 & 7 \\
Error $(\%)$ & - & 1 & 1 & 17 & \\
$R e_{D}=30,000$ & Exp. & $E B-R S M$ & $\phi$ & $k-\omega$-SST & \\
Value & 0.07 & 0.0771 & 0.0615 & 0.0744 & \\
Error $(\%)$ & - & 10 & 12 & 6 & \\
\hline
\end{tabular}


VanFossen [4]: $\quad$ Nus $=0.153 R e^{0.686}$

Metzger et al. [2]: $\quad N u s=0.079 R e^{0.717}$

Note that the local experimental results have an uncertainty of $\pm 12 \%, \pm 11.4 \%$, and $\pm 10.5 \%$ for the $3,000,10,000$, and 30,000 Reynolds numbers, respectively, in the end-wall regions adjacent to the pins and $\pm 9 \%$ away from the pins. For the simulations, the total area of the bottom wall was used for the calculation of the average Nusselt number.

Table 5 compares the computations with the experiments and gives the relative errors. One can see that the two models using an eddy-viscosity ( $\phi$-model and $k$ - $\omega$-SST) are quite far from the experimental results, except for the $\phi$-model at $R e_{D}=30,000$. However, as will be shown later, this model exhibits wrong physics. LES and EB-RSM yielded satisfactory values within the experimental error interval. The superiority of these two models will be discussed later when showing the results of the local normalized Nusselt number on the bottom wall. Ames and Dovrak [5] using standard Realizable $k-\varepsilon$ and RNG $k-\varepsilon$ models also found a substantial underestimation of the average Nusselt number when the pins were heated. Delibra et al. [11] used the URANS $\zeta-f$ model (which is very similar to the $\phi$-model utilized in the present work) at the 10,000 and 30,000 Reynolds numbers and obtained average Nusselt numbers of 46.2 and 122.3 , respectively. These values are also substantially different from the experimental results but it should be mentioned here that these values were obtained by using an imposed constant temperature at the wall. Using this boundary condition in the present work with the $\phi$-model also led to higher values of the average Nusselt numbers (41 and 100, respectively, not shown here). This shows that imposing the temperature gives higher Nusselt numbers than the ones obtained by imposing the heat flux with this model. The effect of the temperature boundary condition was also tested with the LES at $R e_{D}=10,000$ and with the EB-RSM model at $R e_{D}=30,000$. The average Nusselt numbers were found to be equal to 46 and 115.2, respectively. Hence, clear conclusions concerning the effect of imposing the temperature instead of the heat flux at the bottom wall can be drawn for these two models which gave more realistic physics than the eddy-viscosity models. However, one can state that there is clearly a strong influence of the thermal boundary conditions on the results. Delibra et al. [37] also reported LES computations. However, the one carried out for $\operatorname{Re}_{D}=30,000$ was fairly coarse with a short integration time and will thus not be considered here for comparisons. Furthermore, their LES at $R e_{D}=10,000$ gave an average Nusselt number of 44.3 with an error of $18 \%$ compared to the experiments of Ames et al. This led [13] to test a hybrid RANS/LES approach

Table 5 Average Nusselt number comparison on the bottom wall for $R e_{D}=3,000$ (Exp.-Ames et al., DLES-[13], URANS*-[11])

\begin{tabular}{llllllll}
\hline$R e_{D}=3,000$ & Exp. & $L E S$ & & & & & \\
Value & 22.1 & 21.6 & & & & & \\
Error $(\%)$ & - & 2 & & & & & \\
$R e_{D}=10,000$ & Exp. & $L E S$ & $D L E S$ & $E B-R S M$ & $\phi$ & URANS* \\
Value & 54.1 & 48.6 & 44.1 & 48.1 & 37.6 & 33.1 & 46.2 \\
Error $(\%)$ & - & 10 & 18 & 11 & 30 & 39 & 14 \\
& & & & & & & \\
$R e_{D}=30,000$ & Exp. & $E B-R S M$ & $\phi$ & $k-\omega$-SST & URANS* & & \\
Value & 111.5 & 114.8 & 93.3 & 72 & 122.3 & & \\
Error $(\%)$ & - & 3 & 16 & 35 & 9 & & \\
\hline
\end{tabular}


but the results were still less accurate than the ones obtained with their URANS approach based on the $\zeta-f$ model (see Table 5).

\section{Results and Discussions (Local Quantities)}

\subsection{Mean velocity}

Figure 6 displays the dimensional mean stream-wise velocity field in the mid-plane $(Z=$ $D)$. The wakes downstream of the cylinders are similar in LES and EB-RSM and are shorter downstream of the cylinders from row 4 on-wards. This was not observed at all for the $\phi$-model and the $k-\omega$-SST model. Furthermore, both eddy-viscosity models (EVM) overpredicted the pin adjacent gap velocities. One can thus conclude at this stage that the tested EVM models are not able to predict the present flow. Clearly, they predict too long and too weak recirculation regions behind the pins. It is well known that, in the case of wakes
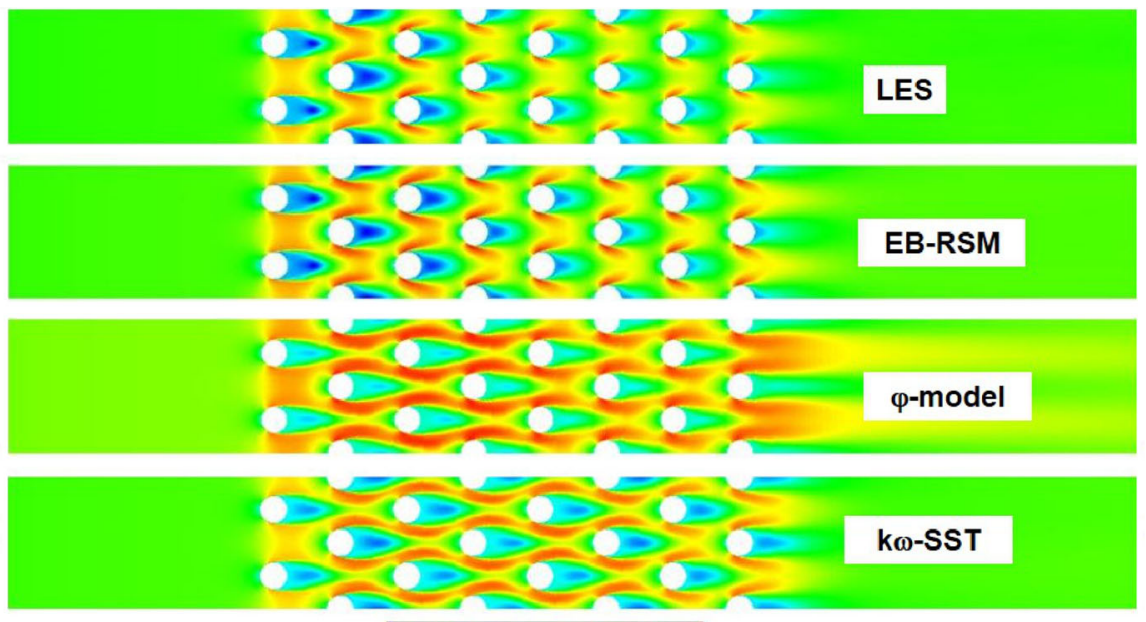

(a)
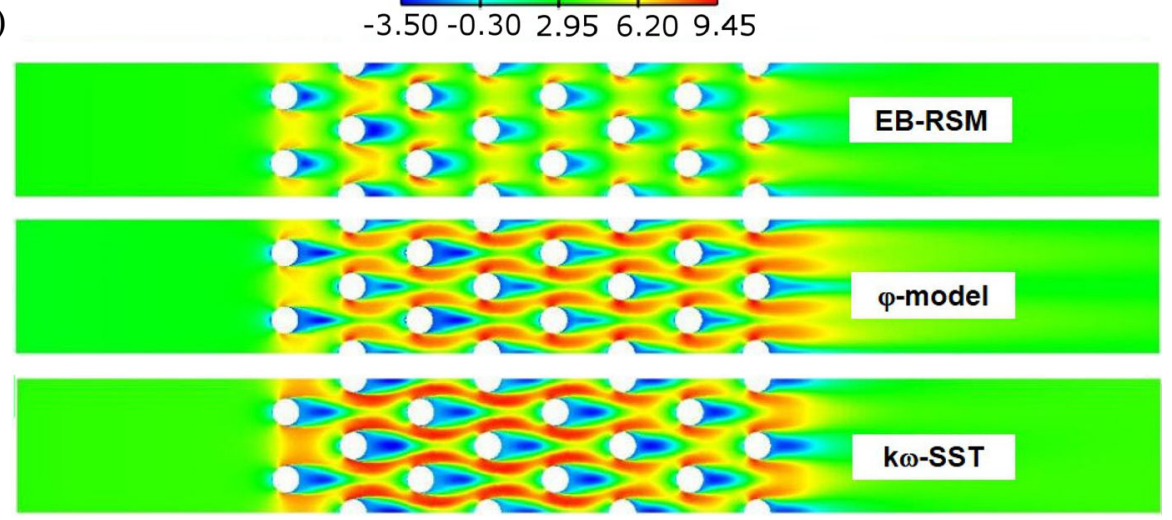

(b)

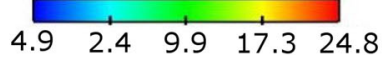

Fig. 6 Dimensional mean stream-wise velocity $(\mathrm{m} / \mathrm{s})$ in the mid-plane $z=D(\mathbf{a}) \operatorname{Re}_{D}=10,000(\mathbf{b}) \operatorname{Re}_{D}=$ 30,000 
of infinite cylinders [14] or wall-mounted obstacles [15], the RANS models (steady state computations) cannot accurately predict the recirculation region, and that URANS can drastically improve the prediction by resolving a significant part of the large-scale unsteadiness, which is a major contributor to the mixing of momentum. It can be anticipated that the main difference between the EB-RSM and the eddy-viscosity models lies in the tendency of the latter to provide a steady solution because of their strongly diffusive character. It can also be argued that eddy-viscosity models tend to overestimate turbulent production close to stagnation points and thus overestimate the turbulent energy in the boundary layers around the cylinders and, consequently, in their wake. This hypothesis will be investigated below.

Figure 7 shows the mean axial velocity component along line B of rows 3 and 5 for the different computations (for further row comparisons see the ERCOFTAC-KB-Wiki

(a)
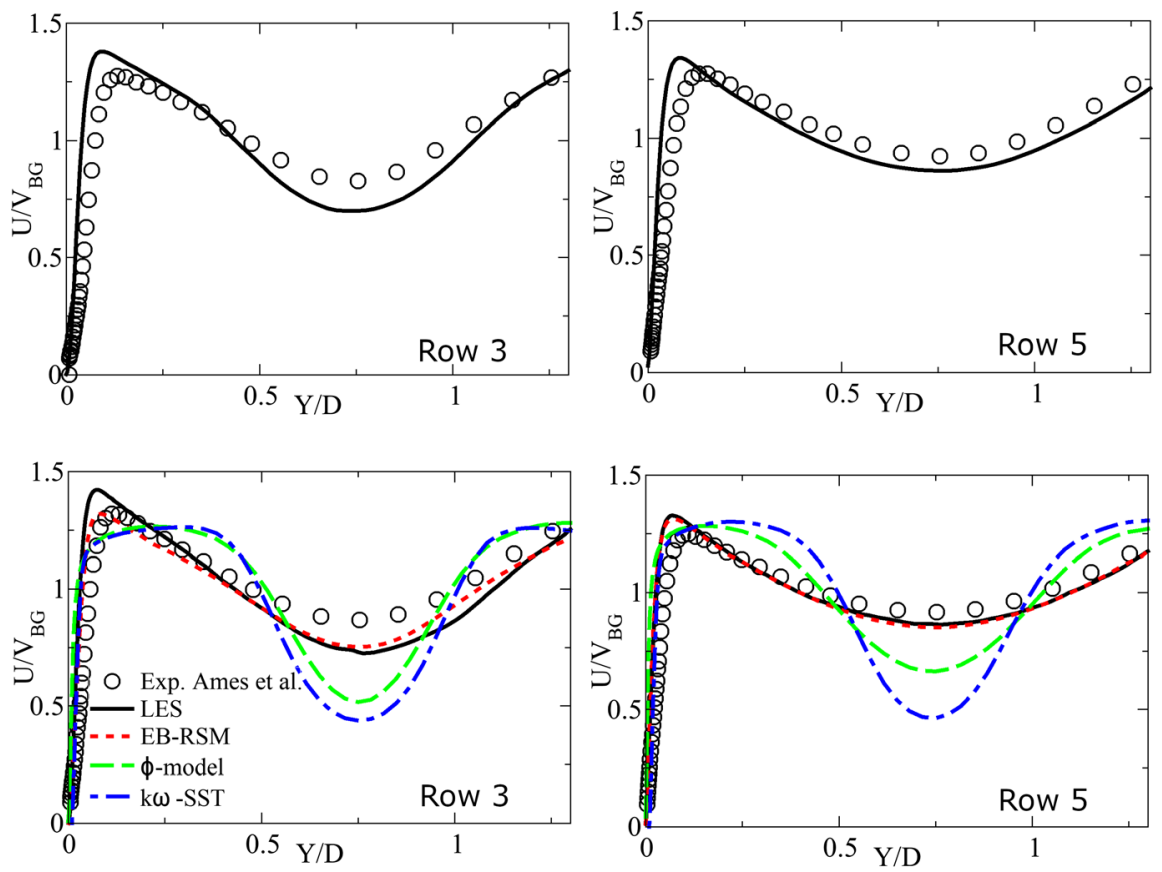

(b)
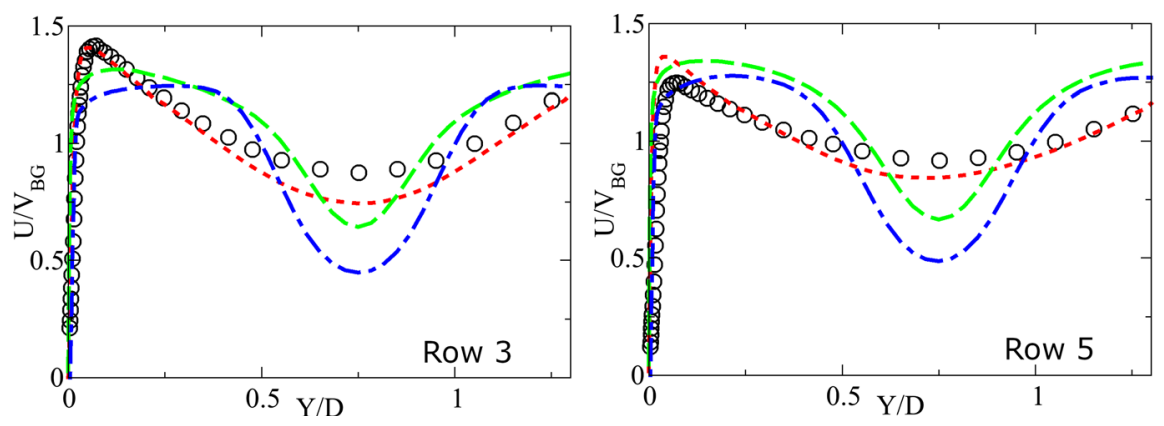

Fig. 7 Mean stream-wise velocity component along line B - LES and URANS computations (a) $\operatorname{Re}_{D}=$ 3, 000 (b) $R e_{D}=10,000$ (c) $\operatorname{Re}_{D}=30,000$ 
database). One observes from Fig. 7b that the EB-RSM model and LES predictions are very close to each other. In fact, for row 3, the EB-RSM model captures the near wall behavior even better than LES, as the peak value by LES is slightly overpredicted. For row 5, both LES and the EB-RSM model slightly overpredict the mean velocity near the pin. On the other hand, the eddy-viscosity models fail to capture the near-wall and the inter-gap flow behavior, see the underprediction at $Y / D=0.1$ and $Y / D=0.75$ in Fig. $7 \mathrm{~b}$, particularly for the row 3 profile.

It is further observed that the two eddy-viscosity models exhibit a dramatic deficit of the mean axial velocity midway between the tubes, in accordance to the overestimation of the size of the recirculation regions as first observed in Fig. 6. On the other hand, LES and EBRSM models perform well compared to the experimental data with a slight overestimation of the mean stream-wise velocity peaks close to the walls at several locations, in particular starting from row 3 . Note that the convergence study shown in Section 3 proved that the refinement needed to obtain a convergent solution around pin 2 is very important (with the first two levels of refinement, a deficit in the central velocity was observed). This is an indication that the accurate reproduction of the large-scale unsteadiness is crucial in this flow: [38] showed that the correct reproduction of the unsteadiness of the wake of an obstacle requires a careful elimination of sources of numerical diffusion. This remark suggests that the origin of the failure of the eddy-viscosity models is in their inability to reproduce realistic large-scale unsteadiness.

Figure 8 shows the mean axial velocity component along line A1 for the highest Reynolds number case. It is observed that the two eddy-viscosity models severely underestimate the mean streamwise velocity, supporting the earlier observations made from Figs. 6 and 7. Both EVM models overpredict the length of the recirculation region behind each pin,

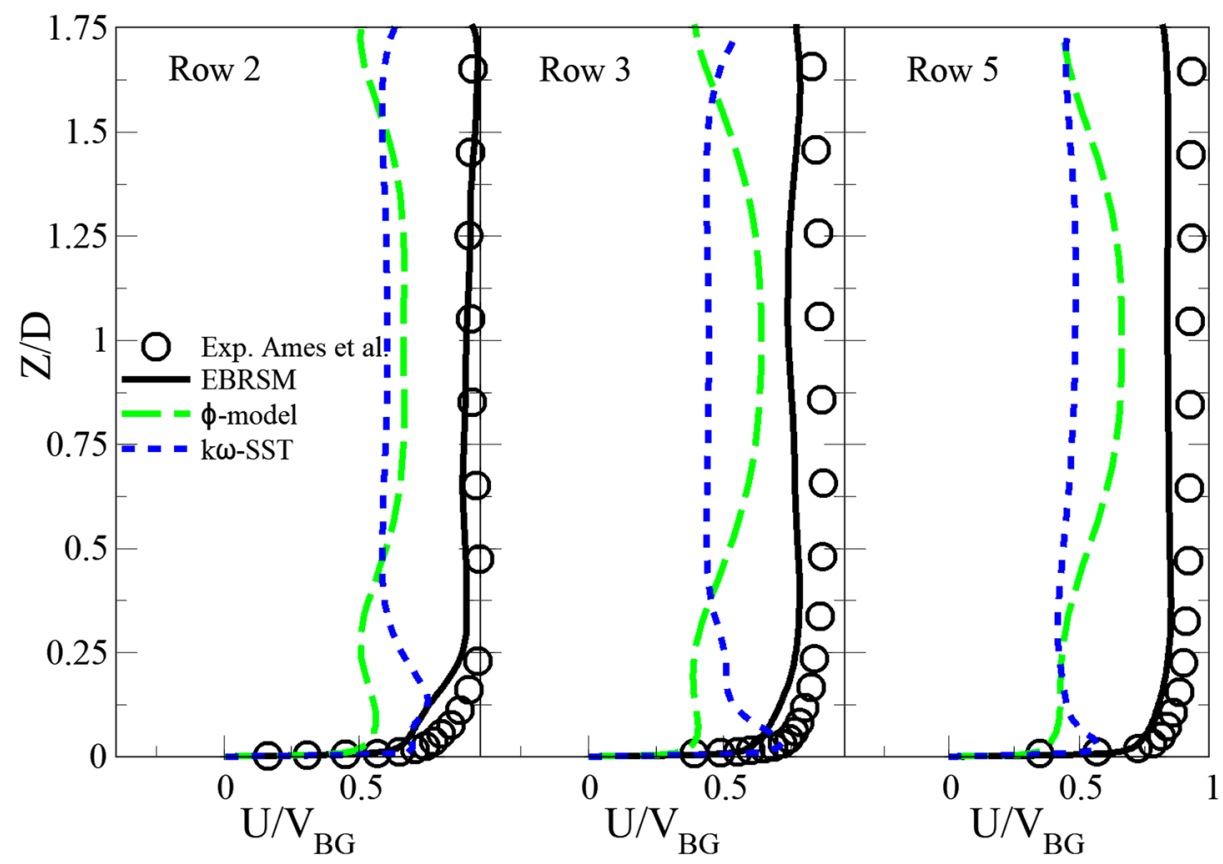

Fig. 8 Mean stream-wise velocity component along line A1 - URANS computations at $R e_{D}=30,000$ 
such that the recovery of the boundary layer in between the subsequent pins is slowed down. In contrast, the RSM model provides a solution very close to the experimental profiles but slightly underestimates the velocity all along the A1 line. However, this must not be interpreted as a deficit of flow rate, which is conserved as the velocity underestimations on line A1 are compensated by overestimations elsewhere.

\section{2 r.m.s velocity}

The best way to gain insight into the very different behavior of the models is to investigate the relative contributions of the resolved and modelled parts of the velocity field to the total r.m.s velocities, as shown in Fig. 9. Here, the contribution of the subgrid scales is neglected for LES (as it is not explicitly evaluated in the present Smagorinsky model formulation). Since no synthetic turbulence is prescribed at the inlet, there is no resolved content before the first pin, and the resolved contribution rapidly develops after the first row. However, as observed from the figure, the flow reaches a fully developed state only around the last row, in accordance with the experiments. The EB-RSM model also exhibits a rapid development of the resolved motion, with r.m.s. levels of the same order of magnitude as those of LES. In addition, a smaller, but significant level of modelled stress contributes to the total fluctuations.

From Fig. 9 it is further observed that the behavior of the two eddy-viscosity models (EVM) is completely different from LES and EB-RSM. For the EVM cases, the contribution of the resolved motion remains small compared to that of the modelled motion, up to at least row 4 and even up to row 7 for the $k$ - $\omega$-SST model. This result indicates that these models face difficulties to reproduce unsteadiness in the wake. As mentioned above, predicting the correct level of mixing in wakes dominated by large-scale vortex shedding, such as behind cylinders or wall-mounted obstacles [14, 15], requires a URANS solution with a very significant amount of resolved unsteadiness. This is the reason why the two eddy-viscosity models exhibit longer recirculation regions in Fig. 6 and consequently underestimate the mean stream-wise velocity in between the subsequent pins (Figs. 7 and 8). Note that at $R e=30,000$, the $\phi$-model remains steady all the way down to the last row. It is interesting to remark here that with a coarser mesh (not shown here), the $\phi$-model rapidly developed unsteadiness. This is in agreement with the findings of [39]; in coarse RANS simulations, dispersive numerical errors (oscillations) can trigger an unsteady behavior, which can paradoxically improve the predictions. The present results show that on fine-enough grids, the solution of eddy-viscosity models remains steady for the first rows and only gradually develops unsteadiness on subsequent rows.

This difficulty to develop an unsteady content, compared to the EB-RSM, can be attributed to an overestimation of diffusion in the wake that prevents the growth of resolved fluctuations. A first possible explanation would be that turbulence is generated in excess by EVM models in the region of the stagnation point [40, 41]. For example, it is clear from Fig. 9, in the right-hand column, that the $\phi$-model produces a high level of turbulence upstream of the first cylinder. Convection of this turbulence downstream may cause an overestimation of the turbulent diffusion in the wake. However, this stagnation point anomaly is, at least, partially corrected in the $k-\omega$-SST model by the introduction of a production limiter: $P=\min \left(P_{k}, 10 \varepsilon\right)$, where $P_{k}=2 v_{t} S_{i j} S_{i j}$ is the standard production term derived from the Boussinesq relation [42]. Indeed, Fig. 9 shows that this model does not exhibit the same overestimation of turbulence production as the $\phi$-model in the stagnation region. Therefore, another explanation is more convincing, even if the two problems can be combined: it appears in Fig. 9, particularly for the SST model, that the overestimation of production 

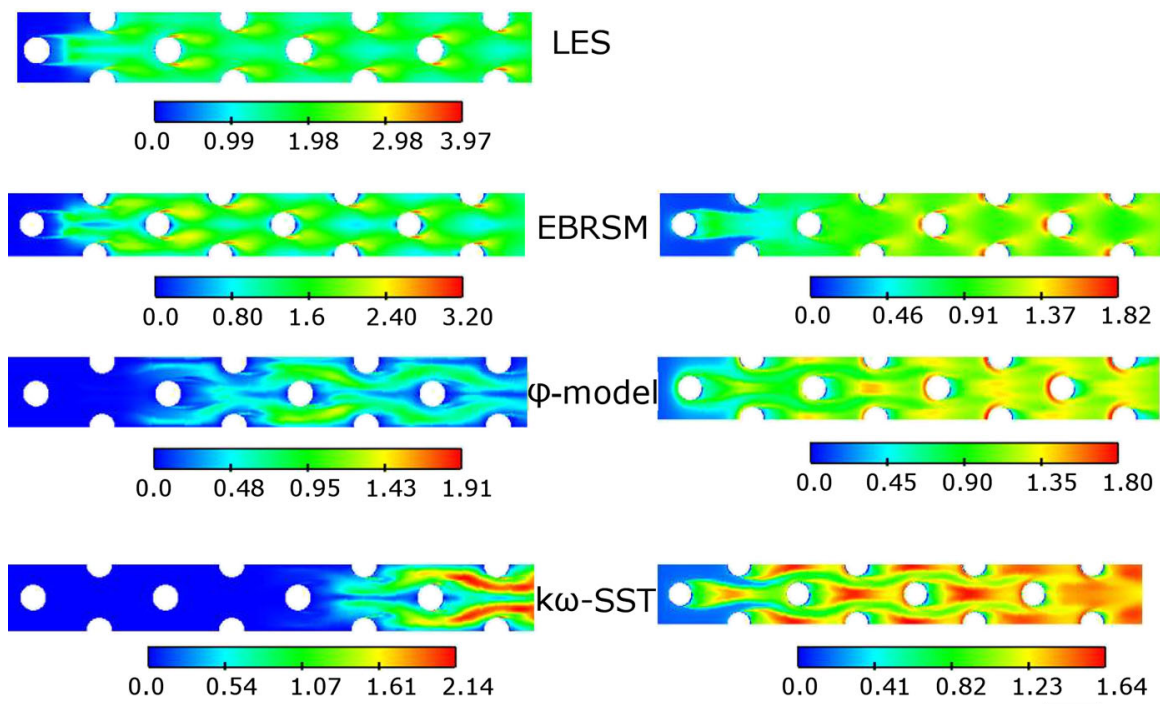

(a)

$\mathrm{u}_{\mathrm{rms}}$

$\mathrm{RSM}: \sqrt{\overline{R_{11}}}, \mathrm{EVM}: \sqrt{\frac{2}{3} \bar{k}}$
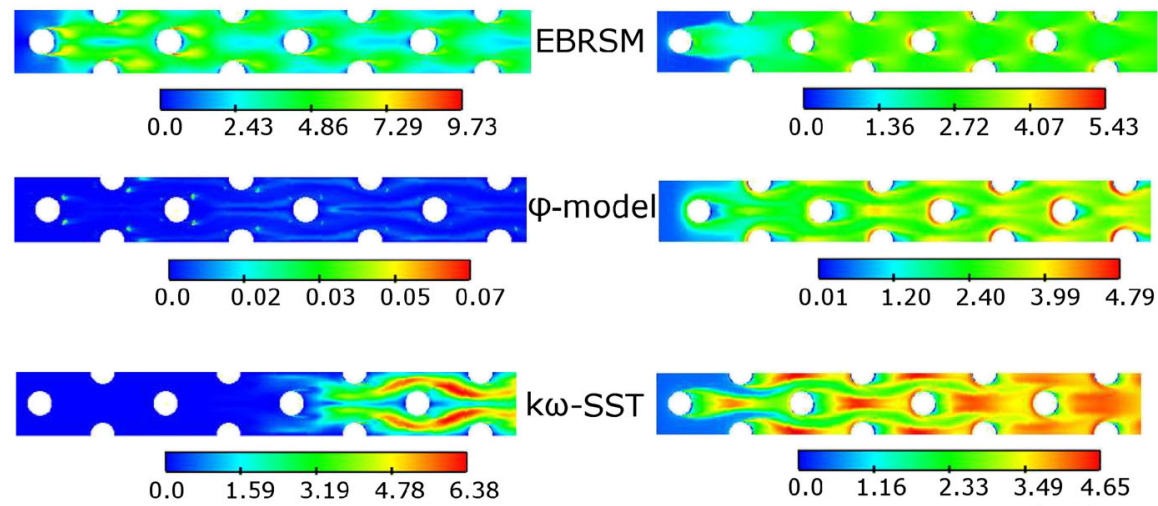

$k \omega-S S T$

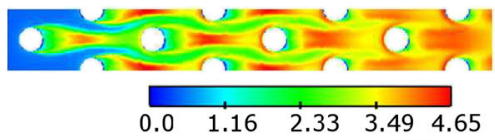

(b)

$\mathrm{u}_{\mathrm{rms}}$

$\mathrm{RSM}: \sqrt{\overline{R_{11}}}, \mathrm{EVM}: \sqrt{\frac{2}{3} \bar{k}}$

Fig. 9 Resolved (left) and modelled (right) contributions to the dimensional r.m.s of the stream-wise velocity component $(\mathrm{m} / \mathrm{s})$ in the mid-plane $(Z=D)$ - LES and URANS computations $(\mathbf{a}) \operatorname{Re}_{D}=10,000$ (b) $R e_{D}=30,000$

takes place mainly in the wake of the cylinders. Indeed, as shown by [43] for the case of a periodic flow (synthetic jet), the Boussinesq relation used in eddy-viscosity models, i.e., the linear relation between the turbulent anisotropy tensor and the mean strain tensor, is at the origin of a strong overestimation of the modelled turbulent production, and, consequently, of the modelled turbulent diffusion of momentum, when the deformation varies rapidly in space or time and the Reynolds stress tensor does not have time to follow this evolution. This overproduction bears some similarity to the problem of the stagnation point anomaly, since it is also to be traced to the use of the linear Boussinesq relation, but is active in other 


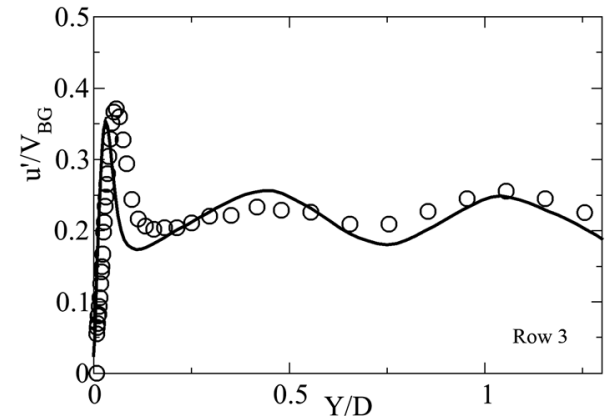

(a)

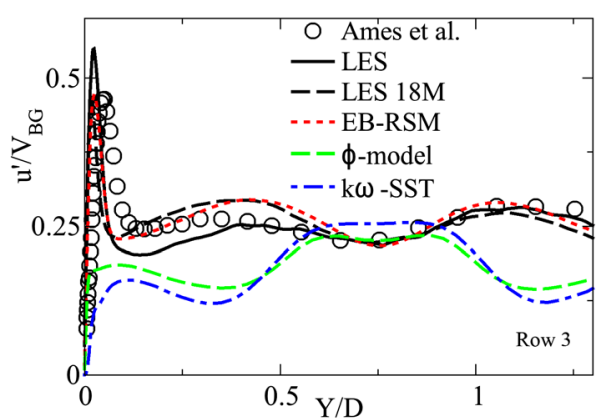

(b)

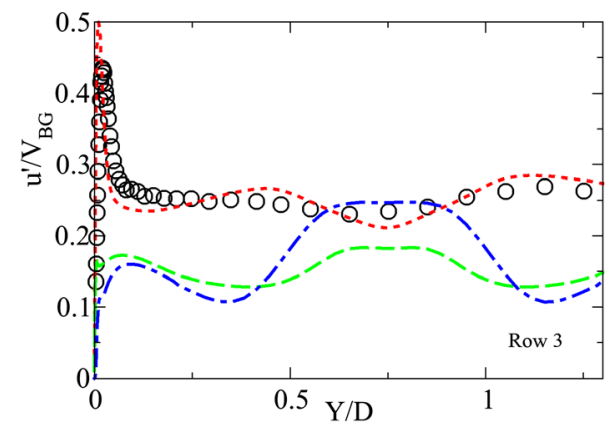

(c)

Fig. 10 r.m.s of the stream-wise velocity component along line B - LES and URANS computations for row 3 (a) $\operatorname{Re}_{D}=3,000$ (b) $R e_{D}=10,000$ (c) $R e_{D}=30,000$

situations, far from the wall, when turbulence is out of equilibrium (see [44, 45] and [46]). For instance, in a 2D-flow, it can be easily shown [43] that the exact production of turbulent energy involves a factor of $\cos (2 \Theta)$, where $\Theta$ is the angle between the eigenvectors of the anisotropy tensor and those of the strain tensor (stress-strain lag), such that eddyviscosity models, which assume $\Theta=0$, overestimate production. This can be generalized to $3 \mathrm{D}$-flows by considering the so-called stress-strain lag parameter $C_{a s}=-a_{i j} S_{i j} / \sqrt{2 S_{i j} S_{i j}}$ [46]. In the case of 2D tube bundles, a case very similar to the present pin-fin-array, it was shown, using experimental data of Simonin and Barcouda, ${ }^{2}$ that the stress-strain misalignment is so strong that large regions of negative production $(\Theta>45 \mathrm{deg})$ are observed in between subsequent tubes (see Fig. 2.17 of Viollet et al. [47]). The lack of consideration of this stress-strain lag prevents the large-scale unsteadiness to be captured in cylinder wakes [46], a problem that can be avoided by using a Reynolds-stress model [43].

Figure 10 shows the r.m.s. profiles of the stream-wise velocity along line B. Here again only the profiles along row 3 are shown and the remaining profiles can be accessed via the ERCOFTAC-KB-Wiki database. The quantity plotted in the figure is $u^{\prime}=\sqrt{\overline{u_{1}^{\prime 2}}+\overline{R_{11}}}$, where $u_{1}^{\prime}$ is the resolved streamwise velocity fluctuation and $\overline{R_{11}}$ the time-averaged value of the stream-wise modelled Reynolds normal stress $R_{11}$. LES and EB-RSM models perform very well compared to the experimental data. As mentioned earlier, it can be seen in

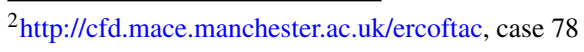


Fig. 11 that for the stream-wise stresses, a major part of the total fluctuations of the EB-RSM model comes from the resolved part, which again shows that this model easily reproduces the large-scale unsteadiness appearing in the wake of the pins. However, in contrast with LES, the modelled part is not negligible. Figure 10 shows that the eddy-viscosity models severely underestimate the total stream-wise fluctuations, except in the central region. It is not expected from these models to provide very accurate r.m.s. velocities, since they are based on the Boussinesq relation, which is not designed to reproduce the individual normal stresses. However, the amplitude of $u^{\prime}$ is underestimated by a factor of more than 2 close to the pin surfaces, which shows that a significant amount of turbulent energy is missing in this region. Figure 11 and more prominently the contours of Fig. 9 provide a rather enlightening explanation for this result. In contrast to the cylinder wake (regions far from the wall), where, as mentioned above, eddy-viscosity models yield a high level of modelled turbulent energy, it can be seen that the contribution of the modelled part close to the pin surfaces is of the same order of magnitude as that of the EB-RSM, but the resolved content remains very small, such that the total, including the resolved and modelled parts, is significantly underestimated. In particular, the near-wall peak, which is largely contributed by the resolved part for the EB-RSM, is completely missed by the eddy-viscosity models. This result is of course consistent with the contourplots of Fig. 9, and definitely supports the conclusion that the main issue with the eddy-viscosity models is their difficulty to grow unsteadiness in the wake of the pins, due to their over-diffusive character.

\subsection{Mean pressure coefficient}

Figure 12 shows the profiles of the mean pressure coefficient along the midline of pins 3 and 5 for the three Reynolds numbers. Profiles along other pins can be accessed via the ERCOFTAC-KB-Wiki database. Note that the experimental results have an uncertainty of \pm 0.075 at $R e_{D}=3,000$ and of \pm 0.025 at $R e_{D}=10,000$ and $R e_{D}=30,000$. LES results are in relatively good agreement with the experimental data. EB-RSM exhibits overall satisfactory results as well. In fact for $R e_{D}=10,000$ for Row 3, the EB-RSM prediction is even better than LES. This result is surprising at first glance, but it is important to emphasize that the LES does not have any fluctuating content at the inlet. Therefore, it takes some rows for the resolved turbulent energy to reach a level compatible with the experiments, in contrast

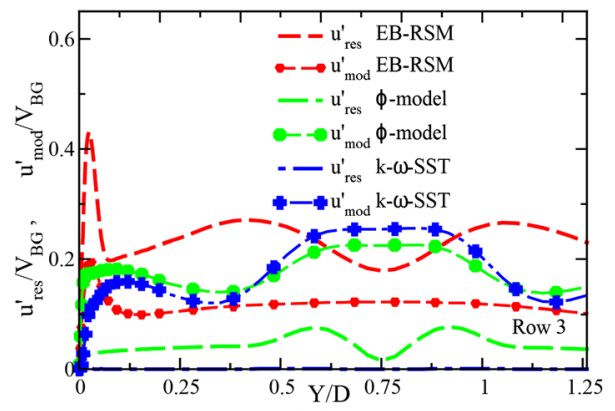

(a)

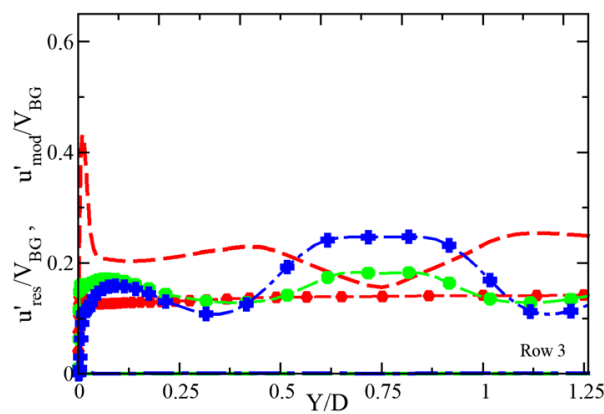

(b)

Fig. 11 Resolved, $u_{\text {res }}^{\prime}$ and modelled, $u_{m o d}^{\prime}$ contributions to the r.m.s of the stream-wise velocity component along line B - URANS computations (a) $R e_{D}=10,000$ (b) $R e_{D}=30,000$ 

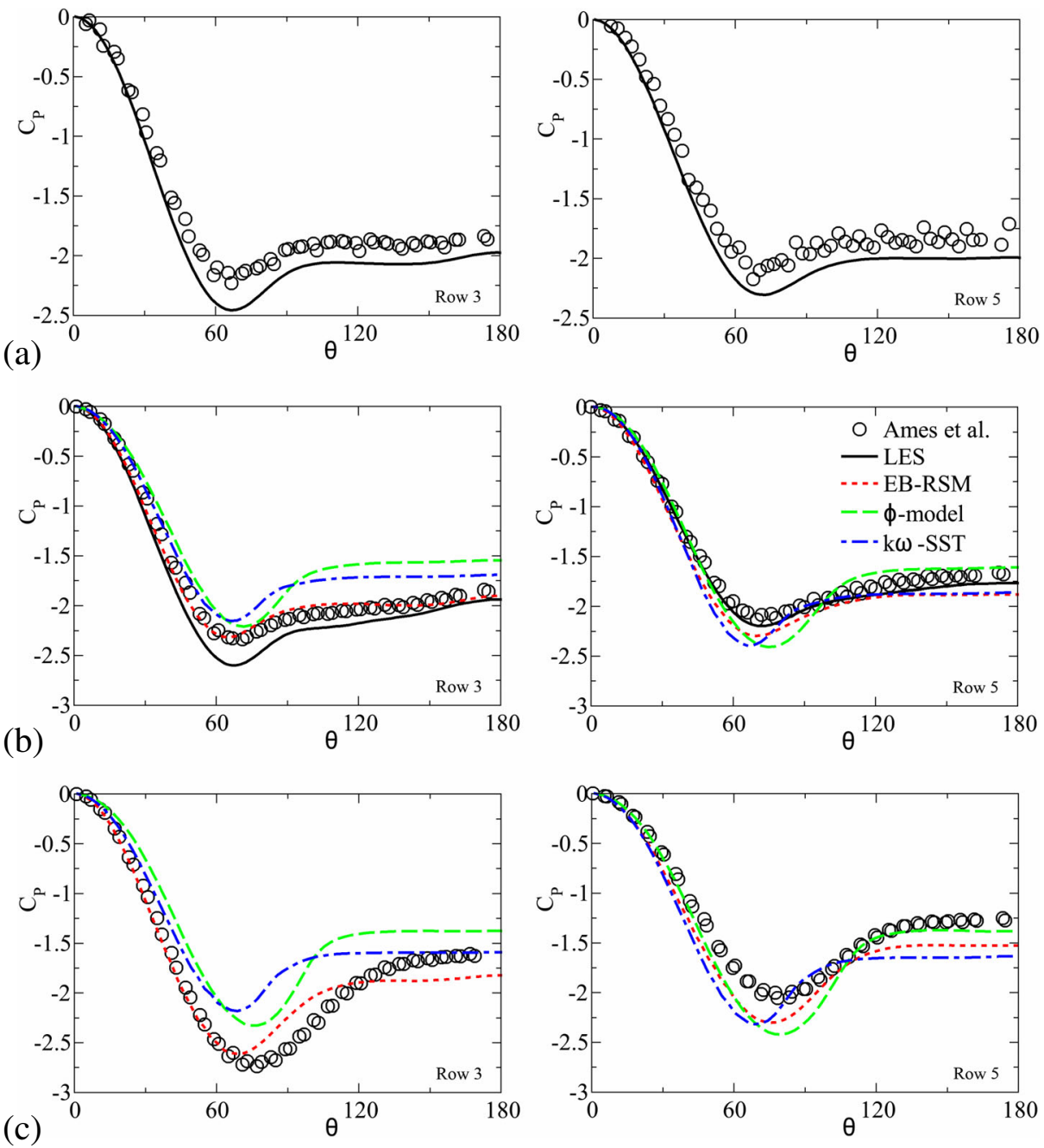

Fig. 12 Pressure coefficient along the line C- LES and URANS computations (a) $\operatorname{Re}_{D}=3,000$ (b) $\operatorname{Re}_{D}=10,000(\mathbf{c}) \operatorname{Re}_{D}=30,000$

to the EB-RSM for which the turbulence intensity at the inlet is 5\%. This discrepancy is not observed at row 5, since the resolved energy content in the LES has developed.

On the other hand, both the eddy-viscosity models show less accurate results, in particular the $\phi$-model. This is expected since the mean flow characteristics are not correctly reproduced, especially the size of the recirculation regions behind the pins, as seen and discussed before. It is also observed that for these models separation was delayed, which led to a weak prediction downstream of the pins. This can also be seen in the contour plots of the mean stream-wise velocity in Fig. 6. On the other hand, the $\phi$-model comparisons are somewhat better for the deeper rows. It can, however, be noticed that at the highest Reynolds number the pressure recovery in general is not predicted very accurately by all the tested models; in addition to the local separation and reattachment, the strong vortex 

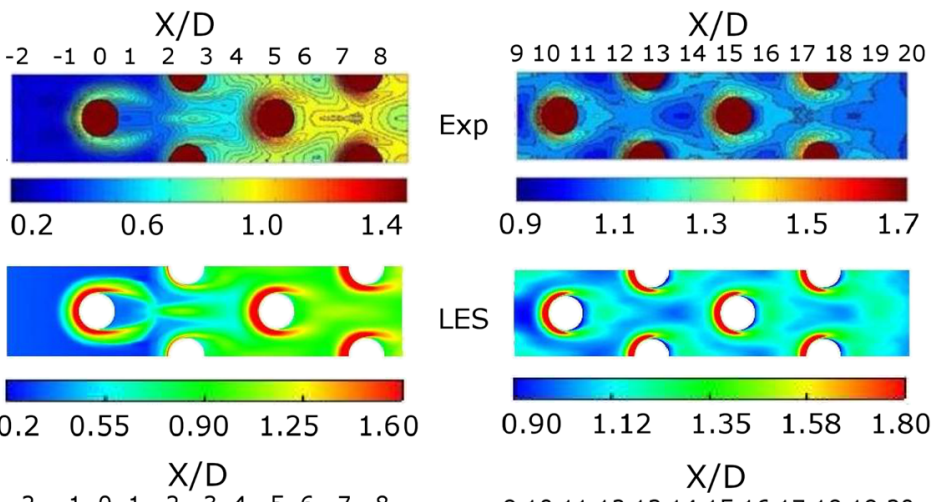

(a) $0.2 \quad 0.55 \quad 0.90 \quad 1.25 \quad 1.60$

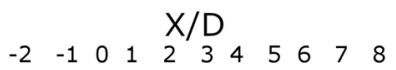

91011121314151617181920
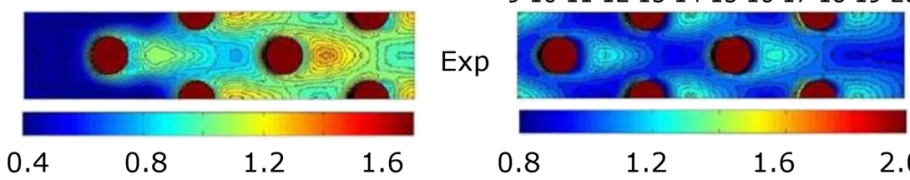

0.8

1.2
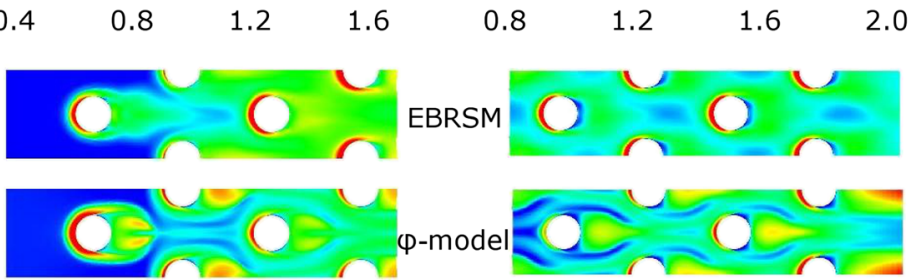

$\varphi$-model
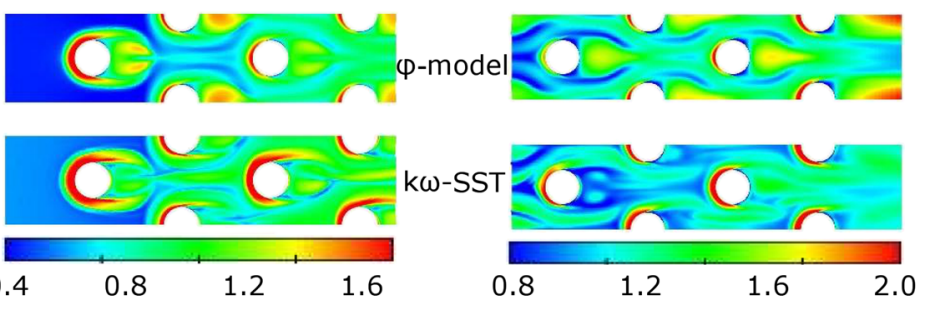

(b) 0.4

$\mathrm{X} / \mathrm{D}$

$\begin{array}{lllllllllll}-2 & -1 & 0 & 1 & 2 & 3 & 4 & 5 & 6 & 7 & 8\end{array}$

$\mathrm{X} / \mathrm{D}$
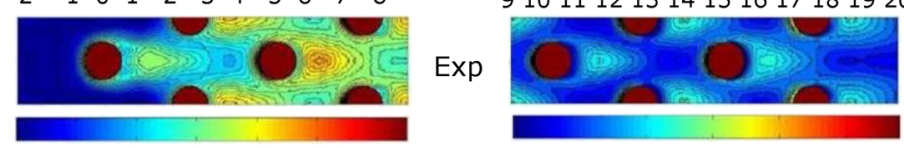

$0.4 \quad 0.8 \quad 1.2 \quad 1.6$
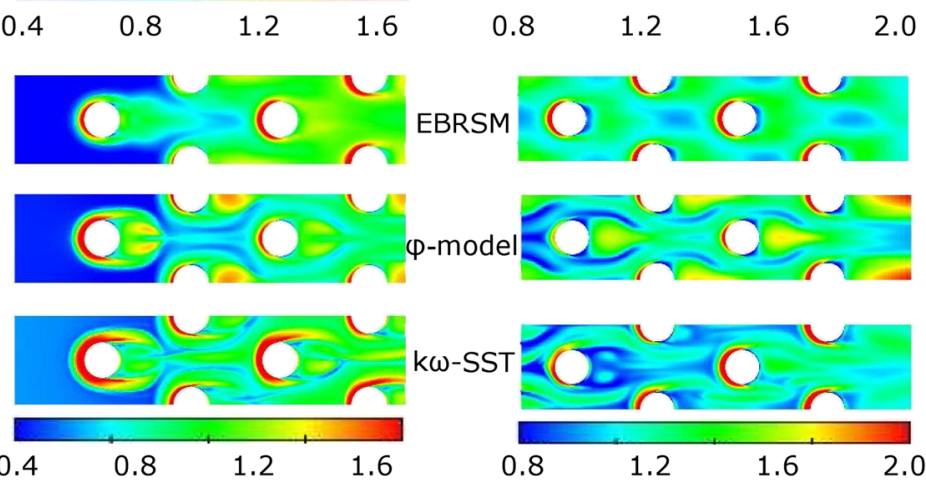

(c) 0.4

Fig. 13 Comparisons of the Local Nusselt number normalized by its average $\left(N u s / N u s_{a v}\right)(\mathbf{a}) \operatorname{Re}_{D}=$ 3,000 (b) $\operatorname{Re}_{D}=10,000$ (c) $R e_{D}=30,000$ 

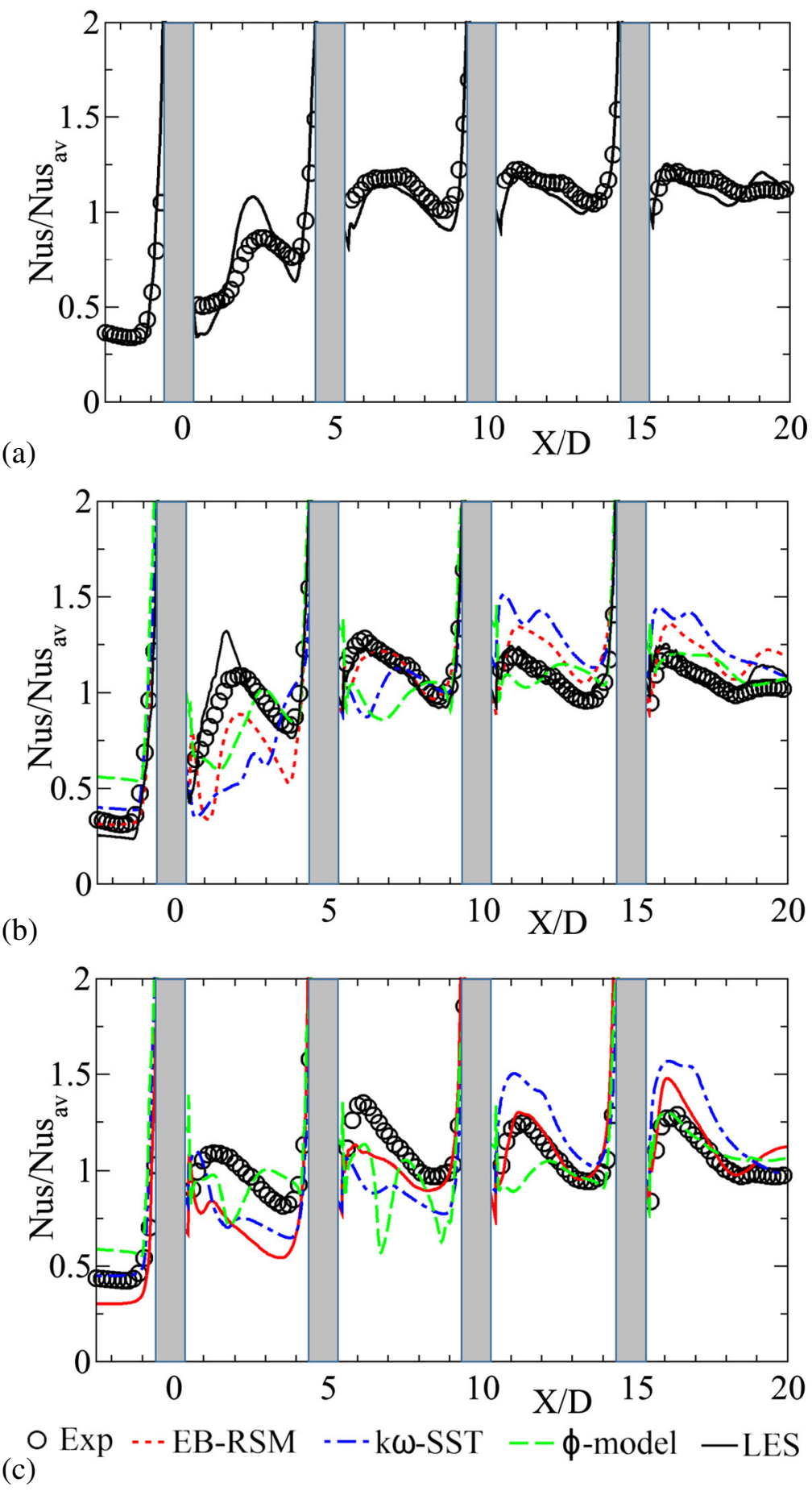

Fig. 14 Local Nusselt number normalized by its average $\left(N u s / N u s_{a v}\right)$ at mid-span $Y / D=0$ plane (a) $R e_{D}=3,000$ (b) $R e_{D}=10,000$ (c) $R e_{D}=30,000$ 
shedding from the sides of the pins make this condition the most difficult to predict with even the most advanced of the RANS closures.

\subsection{Nusselt number on the bottom wall}

Figure 13 shows the contours of the Nusselt number normalized by its average value over the bottom wall. LES computations exhibit an excellent behavior compared to the experimental results. The Nusselt number seems however overestimated at the locations of the horseshoe vortices and underestimated in the wake of the third row, in particular for the highest Reynolds number case. Recall here that the errors made on the average of the normalized Nusselt number were equal to $3 \%$ and $1 \%$ for the $R e_{D}=3,000$ and $R e_{D}=10,000$ cases, respectively.

For the two eddy-viscosity models, owing to the misprediction of the flow topology and the fluctuation level observed in previous sections, it is not surprising that both these models cannot predict the local quantities such as the Nusselt number properly. Moreover, it can be observed that for the $k-\omega$-SST model, the contours are not fully symmetrical, even with a very long averaging time, which suggests the presence of very low frequencies that are probably not physical. On the other hand, the EB-RSM model exhibits a very satisfactory global behavior in particular at the highest Reynolds number. However, the Nusselt number is underestimated in the wake of the first cylinder as the unsteadiness is lower than that predicted by the LES. The prediction for the next rows is satisfactory although an overestimation of the heat transfer in the wake of the cylinders was observed for the last 4 rows.

Figure 14 shows the detailed profiles of the normalized Nusselt number at mid-span $(Y / D=0$ plane). LES exhibits very good results in general, except in the wake of the first pin, where roughly halfway between the two pins, the maximum of the Nusselt number is overestimated for both the tested Reynolds numbers. The Nusselt number is also underestimated just after each pin, but this discrepancy is present for all the models and at all the tested Reynolds numbers. This suggests that the underestimation is not due to the turbulence modelling but rather due to the use of adiabatic conditions on the pin walls, which is not fully representative of the experimental setup.

The results provided by the URANS models are mixed. Clearly, the $k-\omega$-SST is the least satisfactory model, since the results do not match the experiments anywhere. In the wake of the first pin, where turbulence is not yet fully developed, mixing is dominated by the large-scale unsteadiness, which is not reproduced by this model. In contrast, in the wake of the last two pins, turbulence has developed, as seen in Fig. 9, and the model overestimates turbulent mixing and heat transfer. The $\phi$-model better reproduces the Nusselt number in the wake of the last pin, but, in accordance with what has been said earlier, the model does not reproduce the large-scale unsteadiness either, such that the mixing of momentum and heat is underestimated in the wakes of the first few pins. On the other hand the behaviour of the EB-RSM is globally comparable to that of LES, although after the first row, the Nusselt number is significantly underestimated.

\section{Conclusions}

Simulations were carried out for the flow through a wall-bounded pin matrix in a staggered arrangement with an imposed heat flux at the bottom wall, at various Reynolds numbers $(3,000,10,000,30,000)$ based on the gap velocity and the diameter of the pins. 
Two LES simulations (with 18 and 76 million computational cells) and six URANS simulations (utilizing 17 and 29 million cells) were performed. For URANS, the $\phi$-model, $k-\omega$-SST model (both associated to the SGDH with a constant turbulent Prandtl number) and the EB-RSM model combined to the GGDH were used. For LES, the dynamic Smagorinsky model with Lilly's minimization was used. Both global and local comparisons were drawn against experimental data of Ames et al. and hybrid model simulations of Delibera et al.

A global evaluation of the results was performed by computing pressure loss coefficients and average Nusselt numbers. For a more detailed evaluation, the mean pressure coefficient, the mean velocity profiles, r.m.s. of stream-wise velocity, resolved and modelled contributions to r.m.s. values and the Nusselt number at the bottom wall were computed for all the models.

For the global pressure loss coefficient, LES at $R e_{D}=3,000$ and $R e_{D}=10,000$ exhibited excellent comparisons with both experimental and analytical correlations. For the URANS models, it was observed that only the EB-RSM model produced reliable results but only for $R e_{D}=10,000$. For the higher $R e_{D}$ case of 30,000 none of the models seems to perform particularly well; the worst results were obtained by the eddy-viscosity models. For the average Nusselt number the current LES and EB-RSM results were again found to be in good agreement with the experiments for all the tested $R e_{D}$ numbers. Once again, the two eddy-viscosity models did not provide accurate results mainly due to their inability to reproduce the unsteadiness of the flow.

The detailed comparison of the results with the experiments and amongst the models is particularly interesting and the complete set of results can be accessed via the ERCOFTACKB-Wiki. It is observed that the models fall into two categories: those which are able to reproduce the unsteadiness of the wakes of the pins (LES and EB-RSM) and those which essentially provide a steady solution, at least for the first few rows (eddy-viscosity models). The correct reproduction of the global topology of the flow, in particular the length of the recirculation regions behind the pins, is closely related to the presence of a major unsteady contribution. This can be traced to the fact that the turbulent/unsteady structures which efficiently mix momentum in the wake of bluff bodies are the very large-scale structures, which are resolved by LES and EB-RSM, but not by the eddy-viscosity models. This is in line with several previous studies, such as [14] or [15], in which it was shown that the pure RANS models, i.e., RANS models used in a steady-state computation, are not able to correctly reproduce such wakes, while the same models used in URANS mode, i.e., in a time-dependent computation, provide excellent results.

Consequently, reproducing the characteristics of pin-fin-array flows, in which each row of pins is affected by the wake of the preceding row, requires a time-dependent computation in which the unsteadiness develops rapidly, starting from the first row. This behavior is not only observed for LES, but also for the Reynolds-stress model, for which the mixing is dominated by the resolved contribution. In contrast, EVM models face strong difficulties to develop unsteadiness at the first few rows, which severely affects the global predictions. Following previous studies [43-45], this issue can be related to the misalignment of the Reynolds-stress and mean strain tensors in non-equilibrium flows (stress-strain lag), such as cylinder wakes, which is ignored by the eddy-viscosity models; the resulting overestimation of modelled turbulence energy in the wake prevents the development of resolved unsteadiness.

In conclusion, for such a complex configuration, consisting of a staggered arrangement of wall-mounted obstacles, with heat transfer, LES can provide accurate and reliable solutions. URANS can provide an alternative solution, particularly attractive for high Reynolds 
numbers, for which LES can become prohibitively costly, but the choice of the RANS closure is crucial. Due to the importance of avoiding an overestimation of turbulent diffusion in the wakes of the pins, eddy-viscosity models should be avoided and a Reynolds-stress model, or, possibly, a lag eddy-viscosity model [46], should be used. For this case, in the forced convection regime, the model for the turbulent heat fluxes is not crucial; associated with the EB-RSM, which globally provides accurate flow dynamics, the Generalized Gradient Diffusion Hypothesis (GGDH) appears sufficient to reproduce the main heat transfer characteristics.

Acknowledgements The authors would like to thank Électricité de France (eDF) for the computational resources and Prof. Forrest Ames for providing the experimental data for comparisons. The authors would also like to thank Prof. Wolfgang Rodi for his thoughtful review of the test case for the ERCOFTAC KB-CFD Wiki and his invaluable comments about the present article.

\section{Compliance with Ethical Standards}

Conflict of interests The authors declare that they have no conflict of interest.

Open Access This article is distributed under the terms of the Creative Commons Attribution 4.0 International License (http://creativecommons.org/licenses/by/4.0/), which permits unrestricted use, distribution, and reproduction in any medium, provided you give appropriate credit to the original author(s) and the source, provide a link to the Creative Commons license, and indicate if changes were made.

\section{References}

1. Armstrong, J., Winstanley, D.: A review of staggered array pin fin heat transfer for turbine cooling applications. ASME-J. Turbomach. 110(1), 94-103 (1988)

2. Metzger, D.E., Fan, Z.X., Shepard, W.B.: Pressure loss and heat transfer through multiple rows of short pin fins. Heat Transfer 3, 137-142 (1982)

3. Sparrow, E.M., Ramsey, J.W., Altemani, C.A.C.: Experiments on in-line pin fin arrays and performance comparisons with staggered arrays. J. Heat Transfer 102(1), 44-50 (1980). https://doi.org/10.1115/1. 3244247

4. VanFossen, G.J.: Heat transfer coefficients for staggered arrays of short pin fins. In: Turbo Expo: Power for Land, Sea, and Air, vol. 3: Heat Transfer; Electric Power (1981)

5. Ames, F.E., Dovrak, L.A.: The influence of Reynolds number and row position on surface pressure distributions in staggered pin fin arrays. In: ASME. Turbo Expo: Power for Land, Sea, and Air, vol. 3: Heat Transfer Parts A and B, pp. 149-159. https://doi.org/10.1115/GT2006-90170 (2006)

6. Ames, F.E., Dovrak, L.A.: Turbulent transport in pin fin arrays: Experimental data and predictions. ASME J. Turbomach 128(1), 71-81 (2006b). https://doi.org/10.1115/1.2098792

7. Ames, F.E., Dvorak, L.A., Morrow, M.J.: Turbulent augmentation of internal convection over pins in staggered pin fin arrays. ASME J. Turbomach 127, 183-190 (2005)

8. Ames, F.E., Nordquist, C.A., Klennert, L.A.: Endwall heat transfer measurements in a staggered pin fin array with an adiabatic pin. In: ASME. Turbo Expo: Power for Land, Sea, and Air, vol. 4: Turbo Expo 2007, Parts A and B, pp. 423-432. https://doi.org/10.1115/GT2007-27432 (2007)

9. Huang, L., Li, Q., Zhai, H.: Experimental study of heat transfer performance of a tube with different shaped pin fins. Appl. Therm. Eng. 129, 1325-1332 (2018). https://doi.org/10.1016/j.applthermaleng. 2017.10.014

10. Benhamadouche, S., Dehoux, F., Afgan, I.: Unsteady RANS and Large Eddy simulation of the flow and heat transfer in a wall bounded pin matrix. In: ICHMT. Inproceedings Turbulence, Heat and Mass Transfer 7 - Palermo, pp. 1624-1634. Italy. https://doi.org/10.1615/ICHMT.2012.ProcSevIntSympTurbHeat TransfPal.1670 (2012)

11. Delibra, G., Borello, D., Hanjalić, K., Rispoli, F.: Urans of flow and endwall heat transfer in a pinned passage relevant to gas-turbine blade cooling. Int. J. Heat Fluid Flow 30(3), 549-560 (2009). The seventh international symposium on engineering turbulence modelling and measurements, ETMM7. https://doi.org/10.1016/j.ijheatfluidflow.2009.03.015 
12. Hanjalić, K., Laurence, D.R., Popovac, M., Uribe, J.C.: Turbulence model and its application to forced and natural convection. In: Rodi, W., Mulas, M. (eds.) Engineering Turbulence Modelling and Experiments 6, pp. 67-76. Elsevier Science B.V., Amsterdam (2005). https://doi.org/10.1016/B978-008044544-1/50005-4. ISBN 978-0-08-044544-1

13. Delibra, G., Hanjalić, K., Borello, D., Rispoli, F.: Vortex structures and heat transfer in a wallbounded pin matrix: Les with a rans wall-treatment. Int. J. Heat Fluid Flow 31(5), 740-753 (2010). https://doi.org/10.1016/j.ijheatfluidflow.2010.03.004. Sixth International Symposium on Turbulence, 707 Heat and Mass Transfer, Rome, Italy, 14-18 September 2009.

14. Durbin, P.A.: Separated flow computations with the k-epsilon-v-squared model. AIAA J. 33(4), 1-13 (1995). https://doi.org/10.2514/3.12628

15. Iaccarino, G., Ooi, A., Durbin, P.A., Behnia, M.: Reynolds averaged simulation of unsteady separated flow. Int. J. Heat Fluid Fl. 24, 147-156 (2003)

16. Afgan, I., Moulinec, C., Prosser, R., Laurence, D.: Large eddy simulation of turbulent flow for wall mounted cantilever cylinders of aspect ratio 6 and 10. Int J Heat Fluid Flow 28(4), 561574 (2007). Including special issue of conference on modelling fluid flow (CMFF'06), Budapest. https://doi.org/10.1016/j.ijheatfluidflow.2007.04.014

17. Parnaudeau, P., Carlier, J., Heitz, D., Lamballais, E.: Experimental and numerical studies of the flow over a circular cylinder at Reynolds number 3900. Phys. Fluids 20(8), 085101 (2008). https://doi.org/10. $1063 / 1.2957018$

18. Nordquist, C.A.: Pin fin end wall heat transfer distributioin with an adiabatic pin acquired using an infrared camera. In: Master of Science Thesis the University of North Dakota (2006)

19. Archambeau, F., Mechitoua, N., Sakiz, M.: Code_saturne: A finite volume code for the computation of turbulent incompressible flows - industrial applications. Int. J. Finite, 1(1) (2004)

20. Rhie, C.M., Chow, W.L.: A numerical study of the turbulent flow past an isolated airfoil with training edge separation. AIAA paper (1982)

21. Ferziger, J.H., Perić, M.: Computational Methods for Fluid Dynamics. Springer, Berlin (2012). ISBN 9783642560262

22. Benhamadouche, S.: Large eddy simulation with the unstructured collocated arrangement, $\mathrm{PhD}$ thesis, $\mathrm{Ph} . \mathrm{D}$. thesis, The University of Manchester. TH28140 (2006)

23. Germano, M., Piomelli, U., Moin, P., Cabot, W.H.: A dynamic subgrid scale eddy viscosity model. Phys. Fluids A: Fluid Dyn. 3(7), 1760-1765 (1991). https://doi.org/10.1063/1.857955

24. Lilly, D.K.: A proposed modification of the germano subgrid-scale closure method. Phys. Fluids A: Fluid Dyn. 4(3), 633-635 (1992). https://doi.org/10.1063/1.858280

25. Afgan, I., Kahil, Y., Benhamadouche, S., Sagaut, P.: Large eddy simulation of the flow around single and two side-by-side cylinders at subcritical Reynolds numbers. Physi. Fluids 23(7), 075101 (2011). https://doi.org/10.1063/1.3596267

26. Grotzbach, G.: Revisiting the resolution requirements for turbulence simulations in nuclear heat transfer. Nucl. Eng. Des. 241(11), 4379-4390 (2011). 13th International Topical Meeting on Nuclear Reactor Thermal Hydraulics (NURETH-13). https://doi.org/10.1016/j.nucengdes.2010.12.027

27. Menter, F.R.: Two-equation eddy-viscosity turbulence models for engineering applications. AIAA J. 32(8), 1598-1605 (1994)

28. Laurence, D.R., Uribe, J.C., Utyuzhnikov, S.V.: A robust formulation of the v2f model. Flow Turb. Combust. 73(3), 169-185 (2005). https://doi.org/10.1007/s10494-005-1974-8

29. Manceau, R.: Theme special issue celebrating the 75 th birthdays of Brian Launder and Kemo Hanjalic. https://doi.org/10.1016/j.ijheatfluidflow.2014.09.002. http://www.sciencedirect.com/science/ article/pii/S0142727X14001179. Int. J. Heat Fluid Flow 51, 195-220 (2015)

30. Durbin, P.A.: Near-wall turbulence closure modeling without "damping functions". Theor. Comput. Fluid Dyn. 3(1), 1-13 (1991). https://doi.org/10.1007/BF00271513

31. Manceau, R., Hanjalić, K.: Elliptic blending model: A new near-wall Reynolds-stress turbulence closure. Phys. Fluids 14(2), 744-754 (2002). https://doi.org/10.1063/1.1432693

32. Speziale, C.G., Sarkar, S., Gatski, T.B.: Modelling the pressure-strain correlation of turbulence: an invariant dynamical systems approach. J. Fluid Mech. 227, 245-272 (1991). https://doi.org/10.1017/ S0022112091000101

33. Dehoux, F., Lecocq, Y., Benhamadouche, S., Manceau, R., Brizzi, L.-E.: Algebraic modeling of the turbulent heat fluxes using the elliptic blending approach-application to forced and mixed convection regimes. Flow Turb. Combust. 88(1), 77-100 (2012). https://doi.org/10.1007/s10494-011-9366-8

34. Frohlich, J., Mellen, C.P., Rodi, W., Temmerman, L., Leschziner, M.A.: Highly resolved large-eddy simulation of separated flow in a channel with streamwise periodic constrictions. J. Fluid Mech. 526, 19-66 (2005). https://doi.org/10.1017/S0022112004002812 
35. Temmerman, L., Leschziner, M.A., Mellen, C.P., Frohlich, J.: Investigation of wall-function approximations and subgrid-scale models in large eddy simulation of separated flow in a channel with streamwise periodic constrictions. Int. J. Heat Fluid Flow 24(2), 157-180 (2003). https://doi.org/10.1016/S0142727X(02)00222-9

36. Jacob, M.: Heat transfer and flow resistance in cross flow of gases over tube banks. Trans. ASME 59, 384-386 (1938)

37. Delibra, G., Borello, D., Hanjalić, K., Rispoli, F.: LES of flow and heat transfer in a channel with a staggered cylindrical pin matrix. In: Direct and Large-Eddy Simulation VII. Inter. ERCOFTAC Workshop on Direct and Large-Eddy Simulation ERCOFTAC Series, vol. 7. Springer (2010) ISBN: 978-90-481-3651-3

38. Lardeau, S., Leschziner, M.A.: Unsteady RANS modelling of wake-blade interaction: Computational requirements and limitations. Comput. Fluids 34, 3-21 (2005)

39. Fadai-Ghotbi, A., Manceau, R., Borée, J.: Revisiting urans computations of the backward-facing step flow using second moment closures. influence of the numerics. Flow Turb. Combust. 81(3), 395-414 (2008). https://doi.org/10.1007/s10494-008-9140-8

40. Durbin, P.A.: On the $k-3$ stagnation point anomaly. Int. J. Heat Fluid Fl. 17(1), 89-90 (1996)

41. Taulbee, D.B., Tran, L.: Stagnation streamline turbulence. AIAA J. 26(8), 1011-1013 (1988)

42. Menter, F.R., Kuntz, M., Langtry, R.: Ten years of industrial experience with the SST turbulence model. In: Proc. 4th Int. Symp. Turbulence, Heat and Mass Transfer. Antalya (2003)

43. Carpy, S., Manceau, R.: Turbulence modelling of statistically periodic flows: synthetic jet into quiescent air. Int. J. Heat Fluid Fl. 27, 756-767 (2006)

44. Hadžić, I., Hanjalić, K., Laurence, D.: Modeling the response of turbulence subjected to cyclic irrotational strain. Phys. Fluids 13(6), 1739-1747 (2001)

45. Hamlington, P.E., Dahm, W.J.A.: Frequency response of periodically sheared homogeneous turbulence. Phys. Fluids 21(5), 1-11 (2009)

46. Revell, A.J., Craft, T.J., Laurence, D.R.: Turbulence modelling of unsteady turbulent flows using the stress strain lag model. Flow, Turb. Combust. 86(1), 129-151 (2011)

47. Viollet, P.-L., Chabard, J.-P., Esposito, P., Laurence, D.: Mécanique des fluides appliquée. Presses de l'école nationale des ponts et chaussées, Paris (1998)

Publisher's Note Springer Nature remains neutral with regard to jurisdictional claims in published maps and institutional affiliations. 